\title{
Kind or contented? An investigation of the gift exchange hypothesis in a natural field experiment
}

\author{
Francesco Bogliacino, Gianluca Grimalda, David Pipke*
}

June 2, 2022

\begin{abstract}
The gift exchange hypothesis postulates that workers reciprocate above marketclearing wages with above-minimum effort. We test this hypothesis in a natural field experiment where either one or both workers of a pair receive an unexpected monetary bonus. The bonus is assigned selectively based on relative productivity, relative need, or luck. We develop a simple theoretical model of worker effort contingent on inequality aversion and reciprocity motives. Contrary to the gift exchange hypothesis, bonuses decrease productivity, especially when both workers are rewarded. Our postdiction is that workers interpret the bonus as a signal of the employer's contentment with their effort, prompting opportunistic behavior rather than reciprocity. When only one worker is rewarded, the bonus recipient marginally increases productivity (consistently with status-seeking behavior), while the other coworker marginally decreases productivity (consistently with an aversion to disadvantageous inequality). The latter effect is largest when the bonus is assigned based on relative needs.
\end{abstract}

JEL Codes: C93, D63, D91, J31, J33

Keywords: Gift exchange, Employer-worker Relationship, Pay inequality, Natural field experiment, Reciprocity, Fairness, Contentment

*Bogliacino: Universidad Nacional de Colombia (fbogliacino@unal.edu.co); Grimalda (Corresponding author): Kiel Institute for the World Economy (gianluca.grimalda@ifw-kiel.de); Pipke: Kiel Institute for the World Economy (david.pipke@ifw-kiel.de). Francesco Bogliacino acknowledges funding from Fundación Universitaria Konrad Lorenz (Internal Grant 7INV1141: "Desigualdad, aspiraciones y esfuerzo: un análisis experimental"), Open Evidence (Research Grant 009_Inequalities "Desigualdad, Aspiraciones y esfuerzo: Un análisis experimental"), and Universidad Nacional (Internal Grant 26007 "Desigualdad, Aspiraciones y Compromiso Individual"). We are grateful for helpful and constructive comments from Oriana Bandiera, Alexander W. Cappelen, John List, Till Requate, Ulrich Schmidt, Bertil Tungodden, and all the participants at the BEBES seminar in Bogotá, the Brown Bag seminar at Kiel University, the FAIR Workshop at NHH, and the Special ESA Meeting 2022 in Buenos Aires. Suelen Castiblanco, Laura Jiménez and Daniel Reyes provided excellent research assistance. 


\section{Introduction}

According to standard competitive market theory, workers are employed at the marketclearing wage and provide the minimal effort required not to get fired by the firm (Lazear, 2000). Several economic mechanisms such as efficiency wages (Katz, 1986), implicit contracts (Azariadis, 1975), and insider-outsider relationships (Lindbeck and Snower, 1988) can explain evidence at odds with this prediction. Another such mechanism is eminently psychological and rests on the notion of reciprocity (Rabin, 1993). That is the disposition to repay kind actions with kindness and spiteful actions with spite (Fehr and Gächter, 1998, 2000). The seminal work by Akerlof (1982) and Akerlof and Yellen (1990) reported anecdotal evidence consistent with what was called a "gift exchange" (Adams, 1963). Firms paying wages higher than the market-clearing level would be repaid by workers through the provision of effort above the minimal possible. The gift exchange hypothesis has received support in both laboratory experiments (Fehr, Kirchsteiger and Riedl, 1993; Fehr et al., 1998; Charness, 2004) and controlled experiments conducted in natural settings (Gneezy and List, 2006; Cohn, Fehr and Goette, 2015; Gilchrist, Luca and Malhotra, 2016; Englmaier and Leider, 2020). However, some natural experiments have suggested that such productivity gains may be transient (Gneezy and List, 2006; Bellemare and Shearer, 2009) or even negligible (Kube, Maréchal and Puppe, 2012; Esteves-Sorenson, 2018; DellaVigna et al., 2022). Overall, it is still an open question whether individual behavior at the workplace follows the gift exchange hypothesis.

Two topics have not been systematically investigated in this literature. Firstly, the firm may be willing to increase the wages only for some of its workers. This would be the case should the firm's resources be insufficient to increase all workers' wages. Alternatively, it could be a firm's goal to reward the most productive workers. It is unclear how workers will react to selective rewards. To a large extent, experimental studies on gift exchange have only analyzed dyadic relationships where only one principal and one agent interact. Such studies are then silent on how horizontal inequality affects gift exchange. Self-regarding individuals should be indifferent to what happens to others. However, both experimental studies and surveys suggest that many individuals are inequality-averse. That is, they experience envy if someone else is rewarded more than themselves and compassion otherwise (Fehr, Goette and Zehnder, 2009; Fehr and Schmidt, 1999; Bolton and Ockenfels, 2000). If inequality aversion is strong enough, then both disadvantaged and advantaged workers may react negatively to the firm offering selective rewards, thus reducing their effort. Such a strategy may then backfire on the firm.

Secondly, people are generally found to be more tolerant of inequality when this 
can be justified on the grounds of fairness (Konow, 2003). Typically, when inequality is caused by a worker being more productive than another worker because of their higher effort or ability, the resulting inequality is more accepted than when it is caused by luck (Krawczyk, 2010; Alesina and Giuliano, 2011; Durante, Putterman and van der Weele, 2014; Almås, Cappelen and Tungodden, 2020). However, even if the firm tried to follow fair criteria to select who is the most deserving worker to reward, a self-serving bias ${ }^{1}$ may cause unrewarded workers not to recognize the fairness of the process. Workers' resentment may lead to shirking or sabotage (Bewley, 1999). Conversely, if workers find the justification of rewards as fair, they may be willing to respond with positive reciprocity even if the reward is directed to another worker. It is then essential to ascertain how individuals weigh up reciprocity and inequality aversion with respect to different possible sources of inequality, which may be perceived as either fair or unfair. The existing literature has mainly analyzed only one possible source of wage inequality at a time, typically focusing on pay disparity that appeared arbitrary and not explicitly linked to individual merit (Hennig-Schmidt, Sadrieh and Rockenbach, 2010; Cohn et al., 2014).

The present study provides evidence on these topics from a controlled field experiment conducted in a natural work environment. We invited pairs of workers to a university department for a one-day data entry job which workers conducted individually. After workers finished their morning session, the job instructor announced a surprise bonus payment for one worker, worth one-third of the previously announced earnings. ${ }^{2}$ We manipulated the source of earnings inequality across three treatments. The bonus was assigned based on (a) relative productivity in the Productivity treatment (with the more productive worker in the morning session receiving the bonus); (b) relative needs in the Needs treatment (evaluated through a measure of participants' socioeconomic status); or (c) no justification in the Arbitrary treatment (a method which we expected as being perceived as arbitrary by workers). These three treatment conditions are contrasted with two benchmark conditions in which (d) no worker receives a bonus (Control condition), or (e) both workers receive the bonus (Double Bonus condition).

\footnotetext{
${ }^{1}$ Miller and Ross (1975) define the self-serving bias as individual psychological dispositions whereby "[...] people indulge both in self-protective attributions under conditions of failure and in selfenhancing attributions under conditions of success". A self-serving bias, then, prompts individuals to attribute their failure to situational factors, and their success to their own abilities (Deffains, Espinosa and Thöni, 2016). See also Mezulis et al. (2004) and Babcock and Loewenstein (1997).

${ }^{2}$ The announcement of bonuses after the lunch break was a surprise in all treatment conditions and made clear what the final earnings would be to rule out confounds, e.g., due to performance incentives. Hence, the bonus is an unconditional act of kindness by the employer, consistent with the gift exchange hypothesis (Akerlof, 1982), without further contracted obligations or incentives. In somewhat related literature, Bradler, Neckermann and Warnke (2019) compare unconditional gifts and incentives by performance bonuses in two different tasks in the laboratory. See also Kosfeld and Neckermann (2011) and Gibbs, Neckermann and Siemroth (2017) for field experiments studying the effects of rewards creating performance incentives.
} 
In this way, we can weigh motivations from reciprocity and inequality aversion as a response to the bonus by both the bonus recipient and the nonrecipient. We do this for three different sources of inequality, which we expected to be viewed as fair (in the Productivity treatment), unfair (in the Arbitrary treatment), or morally acceptable (in the Needs treatment). Assigning bonuses based on relative needs has rarely been investigated. ${ }^{3}$ We conjectured that this method may have stirred moral approval by both workers, thus spurring workers' dispositions to positive reciprocity.

We believe that the labor market interaction from our naturalistic setting is ideally suited to investigate gift exchange effects in the presence of horizontal pay inequality. Identifying causal effects from firm-level data would be confounded by the existence of many unobservable factors that could drive an observed correlation between effort and wages. This is because firms' strategies are equilibrium responses to exogenous conditions that are jointly determined with workers' behavior. Various unobservable drivers of work morale such as reputational concerns, social norms, rules of behavior, managerial practices, and interpersonal relationships may affect workers ${ }^{6}$ productivity upon changes in the firm wage structure. Even when we could observe discrete changes in remuneration policy, a selection problem in identifying a proper counterfactual would arise because multiple omitted variables may vary at the same time of the treatment across organizations. Our experimental approach minimizes such confounds and allows for causal inference.

The gift exchange hypothesis has received extensive support in the context of laboratory experiments (Fehr, Kirchsteiger and Riedl, 1993; Fehr and Falk, 1999; Charness, 2004; Charness, Frechette and Kagel, 2004) and some support in field studies (Cohn, Fehr and Goette, 2015; Gilchrist, Luca and Malhotra, 2016; Englmaier and Leider, 2020). However, other studies predominantly utilizing data entry tasks found only statistically insignificant effects of monetary pay rises (Hennig-Schmidt, Sadrieh and Rockenbach, 2010; Kube, Maréchal and Puppe, 2012, 2013; Al-Ubaydli et al., 2015; Esteves-Sorenson, 2018; DellaVigna et al., 2022) on productivity, were limited to the supply of extra work (DellaVigna et al., 2022), or effects turned out to be largely transient (Gneezy and List, 2006; Bellemare and Shearer, 2009). Gneezy and List (2006) report initial productivity boosts in response to surprisingly higher than advertised wages in two samples. However, the productivity rise waned quickly after the gift over the six hours of the experiment. The student workers were either hired to perform a data entry task for a library or a fundraising task for a charity. While the productivity boost lost statistical significance as early as after 90 minutes among students hired to

\footnotetext{
${ }^{3}$ In his discussion of distributive justice, Konow (2003) suggests that assigning resources based on relative needs is one principle, among several others, that is usually seen as fair by individuals. Nicklisch and Paetzel (2020) provide experimental support to this claim.
} 
perform the data entry task, it also diminished but remained overall statistically significant with the fundraising task. Bellemare and Shearer (2009) report a similar finding based on an experiment in a real tree-planting firm in British Columbia. A one-day pay rise significantly increased the number of trees planted on that day compared to previous and subsequent days, especially among experienced workers.

Our study also contributes to how horizontal inequality affects productivity at the workplace. Laboratory studies examining pay inequality between two workers generally found that workers are less sensitive to other workers' treatment than themselves. Ceteris paribus, workers' behavior is also less responsive to advantageous inequality than disadvantageous inequality (Charness, Rigotti and Rustichini, 2007; Gächter and Thöni, 2010; Bracha, Gneezy and Loewenstein, 2015). Only few studies investigated the effects of pay inequality within natural field experiments. Hennig-Schmidt, Sadrieh and Rockenbach (2010) did not find evidence for peer comparison effects, neither for advantageous nor disadvantageous wage inequality. Cohn et al. (2014) found that workers whose wage was cut decreased effort twice as much as when both team members' wage was cut. However, this was not the case when only the coworker's wage was cut, pointing to an asymmetric effect. Breza, Kaur and Shamdasani (2018) found that wage inequality led to lower attendance and output when coworkers' productivity was hard to observe in a large-scale field experiment with Indian manufacturing workers. However, such a negative effect of inequality disappeared when workers learned that inequality reflected differences in their baseline productivity. Cullen and Perez-Truglia (2022) find that workers' effort increases when they learn that their managers earn more than them, but the opposite occurs when their coworkers earn more. Overall, preexisting studies investigating selective worker rewards had done so either in a laboratory context devoid of many features characterizing real-life work relationships or in a context where only one possible source of inequality - either luck or productivity - existed. Our framework enables us to systematically assess the relevance of different sources of inequality in workers' productivity responses to selective pay rises.

This paper also contributes to understanding the roles of fairness, legitimacy, and the behavioral responses to procedures at the workplace (Kahneman, Knetsch and Thaler, 1986; Konow, 2000, 2003; Bolton, Brandts and Ockenfels, 2005; Cappelen et al., 2007; Trautmann, 2009) and the theoretical literature using social preferences to explain labor market outcomes. Our theoretical model merges two types of social preferences that have rarely been considered jointly thus far (Charness and Rabin, 2002; Falk and Fischbacher, 2006; Cox, Friedman and Gjerstad, 2007; Cohn et al., 2014), i.e., reciprocity (Rabin, 1993) and inequality aversion (Fehr and Schmidt, 1999). We hypothesized that workers would be willing to "punish" (Fehr and Fischbacher, 2004) the firm with lower effort when not receiving the bonus while the other worker received the bonus. For the 
bonus recipient, our model accommodates decreasing effort if the worker is inequality averse as in Fehr and Schmidt (1999), or an increase in the effort if the worker desires to repay the firm for having been singled out as the bonus recipient as in the status-seeking model of Frank (1985).

Contrary to the gift exchange hypothesis, our main result is that pay rises decreased productivity. This effect was most substantial in the Double Bonus condition, where both workers received the bonus. It also occurred in all three treatments where only one worker received the bonus. Our post-diction is that this result is due to what we define as a contentment effect. Workers may interpret the bonus as a signal that the manager is content with their work and is unlikely to punish or even fire them, thus feeling entitled to reduce their effort.

Furthermore, we do not find evidence that advantageous pay inequality leads to inequality aversion and thus negative reciprocity. Conversely, the productivity of bonus recipients in all three treatments is higher than in the Double Bonus condition, reaching statistical significance in the Productivity treatment. This result may be interpreted as weak evidence for status-seeking preferences as opposed to an aversion against advantageous pay inequality (Frank, 1985; Abbink and Sadrieh, 2009; Abbink and Herrmann, 2011; Heffetz and Frank, 2011). Similarly, there are no significant effects of disadvantageous inequality among nonrecipients when the bonus is assigned arbitrarily or to the more productive worker. Only when the bonus is assigned to the worker who is needier, nonrecipients significantly reduce their effort relative to the Control condition. This result suggests that workers view a justification of pay inequality based on needs as inappropriate in the labor market. Our main results are robust to several checks, including adjusting p-values for multiple hypothesis testing (see Section 4.4). Concerning the generalizability of our empirical results, we report on selection, attrition, naturalness, and scaling, the SANS conditions posed by List (2020), in the discussion (also see Goldszmidt et al. (2020) and Holz et al. (2020)).

The remainder of our paper is structured as follows. The following Section 2 describes the experimental design. In Section 3, we develop a theoretical model of worker effort based on which we develop our hypotheses regarding the experiment. Empirical results are presented in Section 4. Section 5 discusses the results, emphasizing their generalizability particularly to cultural contexts different from Colombia. Section 6 concludes.

\section{Experimental design and procedures}

Recruitment. - The study received ethical approval (\#7INV1141) from the university review board of the Fundación Universitaria Konrad Lorenz, where the research 
sessions were conducted. The university is located in Colombia's capital Bogotá. Participants were recruited through advertisements at the university and social networks, ensuring that our sample includes both university students and people with lower levels of education (see Appendix Table A.1 for sample characteristics). The advertisement invited people to register for a one-time work opportunity ruling out reemployment. This aspect should exclude reputational concerns and repeated game strategies. In addition, the advertisement mentioned that some basic abilities in computer work were needed. Participants were requested to send a CV as a part of their job application. No applicant was turned down, and no participant left the session after its start. The advertised hourly rate of 15,000 Pesos per hour (about 6 USD) stood well above the standard payment for temporary work. A pilot study ascertained that such a wage rate was necessary to ensure a smooth recruitment process and attract applicants with the required skill level, considering the possibility of significant commuting times in Bogotá. Workers' payment was independent of the number of entries that workers completed. A desired effort level was not mentioned throughout the recruitment process or the initial induction session. The final sample contains 236 participants $^{4}$ in 126 daily sessions between October 2014 and January 2015. In 15 cases where a recruited (co-)worker did not show up at the appointed time, a confederate acted as a coworker. The 15 participants were unaware of working with a confederate. ${ }^{5}$ Confederates were not part of the analysis sample.

The sessions. - On each working day of fieldwork, two participants were invited to come to the university at $10 \mathrm{am}$. The same female research assistant acted as an instructor in all sessions. The fact that the working sessions were part of an experiment and that pay conditions would be manipulated across sessions was concealed to participants. A female or a male aid was also present on a rota basis. Workers were asked to sign an informed consent form for the handling of their personal data before the instructor started explaining the job. The signing of the standard consent form was customary by the University's regulations. It would have also been necessary if the work opportunity had been offered without any research purposes, thus not affecting the naturalness of the work opportunity. The work consisted of entering the street addresses of some randomly selected phone users into an Excel spreadsheet. Workers were prevented from talking with each other throughout the working day and carried out their work in separate rooms. This procedure prevented peer pressure or group bonding effects and workers communicating information on their productivity (Falk and Ichino, 2006). In addition, workers' computers were connected via the internet to

\footnotetext{
${ }^{4}$ We had to remove one observation for which technical problems with the USB connector made it impossible to recover the exact output distribution between the morning and the afternoon session.

${ }^{5}$ The robustness checks in Section 4.4 show that our results are unaffected by excluding the 15 recruited workers who unconsciously worked with a confederate.
} 
our server computer. In this way, workers' hourly output could be monitored by researchers. The morning session lasted two hours. After a fifteen-minute lunch break ${ }^{6}$, workers were separately reconvened to the job instructor's room, where the instructor announced treatment-specific instructions for the afternoon session in front of the workers Treatment conditions were randomized and administered according to a sequence that was randomly selected before the start of fieldwork. The afternoon session lasted three hours. At the end of the workday, workers filled out a questionnaire inquiring about demographic characteristics and their evaluation of the work session. Finally, they received their payment.

The treatments. - In the Control condition, work continued without any announcement during the break. In the Double Bonus condition, a bonus payment of 25,000 Pesos (about 10.5 USD, worth one-third of advertised earnings) was paid to both workers, mentioning no specific reason. Finally, workers were told that a 25,000 Pesos bonus would be paid to one worker in single-bonus treatments. Three different justifications for the bonus assignment were provided: The worker who had the higher number of entries in the morning session received the bonus in the productivity treatment. In the Needs treatment, the worker residing in the block $^{7}$ classified as less affluent according to the official evaluation of Bogotá city council ("estratificación socioeconómica") received the bonus. ${ }^{8}$ In the Arbitrary treatment, a worker was assigned the bonus without giving any information on the used criteria. Instead, we mentioned that neither relative productivity nor relative needs determined the bonus assignment. ${ }^{9}$ The surprise bonus' announcement (see instructions) emphasized the workers' final earnings (including the bonus payment). This feature was to rule out that workers expected additional bonuses. Hence, it excludes the possibility of confounds, e.g., from performance incentives, which could otherwise influence the unconditional nature of the bonus (without

\footnotetext{
${ }^{6}$ Lunch was provided for free by the researchers. The preference for a relatively short lunch break emerged during the pilot study, as workers typically preferred a short break to finish earlier.

${ }^{7}$ Each Bogotá dwelling is assigned a ranking (so-called "Estratificación socioeconómica"), ranging from 1 to 6 , which classifies the value and quality of the housing to differentiate the payment of utility bills. The ranking used in the research session was taken from a copy of a utility bill, which participants were asked to bring to the work session. This procedure ensured that the Bonus assignment in the Needs treatment was based on truthful reporting. We asked participants to bring such a bill and hand it over to the instructor at the beginning of the session.

${ }^{8}$ The evaluation of socioeconomic stratification is commonly used as a proxy for socioeconomic status in Colombia (Hagenlocher et al., 2013; Martinsson, Villegas-Palacio and Wollbrant, 2015; Bogliacino, Jiménez Lozano and Reyes, 2018). If both blocks had the same evaluation, the bonus was assigned to the worker whose block was located in the poorer (according to the city council's classification) district. The majority of roughly 90 percent of Colombia's population lives in one of the first three strata considered poor, with considerable differences in the quality of dwellings even between these three.

${ }^{9}$ Each worker had a $50 \%$ probability of being assigned the bonus. We did not release this information because workers may have perceived an unbiased random procedure as a fair criterion (Bolton, Brandts and Ockenfels, 2005; Krawczyk, 2011; Trautmann, 2009; Schurter and Wilson, 2009). Our intention was instead to maximize the perceived unfairness of the procedure. The Arbitrary treatment was indeed perceived as the least fair of the three (see Section 4.3).
} 
further contracted obligations).

These three treatments were meant to evaluate workers' reactions to three different methods to introduce inequality in the wage structure, expecting that acceptance of inequality would be higher in treatments with higher perceived fairness. As Bewley (1999) argued, workers' perceived fairness of the internal pay structure depends on whether pay differences are based on reasonable and impartial criteria. The Productivity treatment arguably can be deemed as reasonable and impartial, as paying a productivity premium is common in the labor market and is justifiable by the objective to reward the worker bringing the higher profit to the firm. At the other side of the spectrum, the Arbitrary treatment is unlikely to be seens as reasonable and impartial, precisely because no reason is offered for the bonus assignment. This treatment was meant to mirror situations in the workplace where workers perceive promotions or differential treatments of workers as unfair.

Finally, the Needs treatment introduces a rarely used method in the labor market. Nonetheless, relative needs are psychologically salient for many people (Konow, 2003) and have wide-ranging policy relevance. Allocation of resources based on needs is often invoked as a principle of distributive justice (Nicklisch and Paetzel, 2020). Affirmative action or means-based intervention may be interpreted as preferential treatments based on needs. The purpose of the Needs treatment is to investigate workers' reaction to rewards that arguably redresses real-life inequalities, and may therefore be considered equitable for reasons different from economic productivity (Konow, 2003). We conjectured that the Needs treatment would be perceived as lying in the middle of the fairness spectrum, with the Productivity and Arbitrary treatments lying at its extremes.

Instructions, scripts, and experiment protocol are available in the Online Appendix (Section B.2). The data and code were deposited at the Open Science Framework and are available for the purpose of replication upon request.

\section{Theoretical framework}

We propose a simple theoretical model of worker effort that shall guide our experiment's analysis. In the tradition of the gift exchange hypothesis (Akerlof, 1982; Akerlof and Yellen, 1990), the model captures the idea that workers' effort choice under fixed hourly pay depends on the generosity of the wage in comparison with the standard. We also assume that individuals are concerned with horizontal pay inequality, i.e., how the own wage compares to the coworkers' wage. Finally, we build on a series of more general models incorporating reciprocity motives (Rabin, 1993; Dufwenberg and Kirchsteiger, 2004) or inequality aversion (Fehr and Schmidt, 1999) into individuals' utility functions. 


\subsection{The setup}

Akin to DellaVigna et al. (2022), we propose a utility function for a worker that depends on three components:

$$
U_{i}=w_{i}-c\left(e_{i}\right)+K_{f_{i}} \cdot e_{i}
$$

The first two components are purely self-regarding, as they only depend on variables attaining to the agent. $w_{i}$ is the wage earned by the worker, and $c\left(e_{i}\right)$ the disutility from exerting effort. As standard, we assume an invertible convex cost function $c\left(e_{i}\right)=r e_{i}^{2}$ with $r>0$ that is increasing in effort and fulfills the regularity conditions ensuring a unique solution. Those are $c^{\prime}(e)>0, c^{\prime \prime}(e)>0$ and $\lim _{e \rightarrow \infty} c(e)=\infty$. The third component of (1) is other-regarding as it includes variables pertaining to other agents' payoffs. We call it the social preferences component. It is the product of social preferences towards the firm $K_{f_{i}}$ and worker's effort $e_{i}$.

$$
\begin{aligned}
K_{f_{i}} & =\kappa+\varphi\left\{l \cdot\left(w_{i}-w_{\text {norm }}\right)+m \cdot\left(w_{j}-w_{\text {norm }}\right)\right\} \\
& +\left\{-\left(I_{w_{i}>w_{j}} \cdot \beta-I_{w_{j}>w_{i}} \cdot \alpha\right) \cdot\left(w_{i}-w_{j}\right)\right\}
\end{aligned}
$$

The social preferences towards the firm $K_{f_{i}}$ consist of three parts. The first is a constant $\kappa$ which may capture unconditional value attributed to the firm's payoff. This value may originate from altruism (Becker, 1974), social norms demanding positive effort in employment relations (Bénabou and Tirole, 2006), or even utility from doing useful work (Ariely, Kamenica and Prelec, 2008). ${ }^{10} \kappa$ may also be interpreted as capturing fears of getting punished when not providing an acceptable level of effort to the employer (Lazear, 2000). In addition, we assume that workers' concerns about the employer's payoffs are affected by two terms. The first term captures the "gift exchange" Akerlof (1982) component. It expresses the worker's sensitivity to the firm paying wages above or below an exogenous norm. Such a social norm may coincide with the market equilibrium or the level set in previous bargaining or past interactions. Wages equal to the norm are perceived as neither kind nor unkind. In general, this motivation should apply to both the worker's own and the other worker's wage (Akerlof, 1982). Accordingly, the higher $\left(w_{i}-w_{\text {norm }}\right)$ and $\left(w_{j}-w_{\text {norm }}\right)$, the higher the perceived kindness, and the stronger are the social preferences towards the firm. We assume a self-serving bias by agent $i$, such that the agent's own wage matters no less than the other agent's wage, i.e. $l \geq m \geq 0 . l=m$ corresponds to agent $i$ holding the treatment of agent $j$ precisely on a par with the treatment of her own wage. If $l>m \geq 0$, agent $i$ will consider her

\footnotetext{
${ }^{10}$ See DellaVigna et al. (2022) for a similar theoretical approach.
} 
own pay as more relevant than the coworker pay's as relevant to assess judge the firm's kindness. In the case of $m=0$ and $l>0$, agent $i$ will only be concerned with her own wage. According to the gift exchange hypothesis, the weight that measures the relative relevance of the gift exchange component for the social preferences is positive: $\varphi>0$. Nonetheless, one may put forward an alternative hypothesis. A worker receiving a wage higher than $w_{\text {norm }}$ may think that the firm wants to manifest its contentment for the worker's behavior. The worker may, in this case, feel entitled to provide less effort, rather than more, possibly because the worker now has less fear of being fired. Hence, a wage rise may be taken as a justification to reduce effort, rather than increase it. We can model the "contentment hypothesis" with $\varphi<0$.

The third term in $K_{f_{i}}$ refers to the horizontal inequality between coworkers' wages. $I_{()}$is an indicator function that takes the value of 1 if the subscripted condition is fulfilled. Individuals are concerned with both advantageous $\left(w_{i}>w_{j}\right)$ and disadvantageous $\left(w_{i}<w_{j}\right)$ inequality (Fehr and Schmidt, 1999). Advantageous and disadvantageous inequalities are weighted with $-\beta$ and $-\alpha$, respectively. Fehr and Schmidt (1999) posit that individuals dislike both advantageous and disadvantageous inequality, experiencing compassion when earning more than the other worker, and envy when earning less. Setting $\alpha \geq 0$ and $\beta \geq 0$ accordingly, individuals perceive the firm as less kind if the wage differential is positive. Individuals may be expected to be more sensitive to disadvantageous inequality than advantageous inequality (see evidence by Loewenstein, Thompson and Bazerman, 1989; Fehr and Schmidt, 1999) so that $\alpha \geq \beta \geq 0$. Another possibility is that individuals are not driven by compassion when earning more than another individual but rather enjoy relative status (Frank, 1985) or experience spite. In this case, individuals attach a positive utility to earning more than the other, rather than disutility. Experiments demonstrate that a non-negligible share of individuals indeed displays spiteful preferences (Abbink and Sadrieh, 2009; Abbink and Herrmann, 2011; Fehr, Glätzle-Rützler and Sutter, 2013). We can capture status concerns or spite when earning more and envy when earning less than a coworker by setting $\alpha \geq 0 \geq \beta$.

Given that (2) and $e_{i}$ enter (1) multiplicatively, the worker will maximize his or her utility by exerting positive effort as long as his or her social preferences or sentiments for the firm are positive, i.e., $K_{f_{i}}>0$. The utility function for the second worker $j$ is assumed to be identical to that of worker $i$ with reversed indices $i$ and $j$. In our experimental setup, wages can only take two values. Either the wage is equal to the fixed wage $w$, or the worker additionally receives a lump-sum bonus $B$. Then, the wage of worker i can be expressed as $w_{i}=w+I_{\text {Bonus }_{i}} \cdot B$. Worker $i$ 's maximization problem 
can be written as:

$$
\underset{e_{i} \in \mathbb{R}}{\operatorname{argmax}} w_{i}-c\left(e_{i}\right)+K_{f_{i}} \cdot e_{i}
$$

Maximizing utility with respect to effort gives the first order condition defining the optimal level of effort $e_{i}^{*}$ provided by worker $i$ :

$$
\frac{\delta U_{i}}{\delta e_{i}}=-c^{\prime}\left(e_{i}\right)+K_{f}=0 \Longleftrightarrow e_{i}^{*}=c^{\prime-1}\left(K_{f}\right)=\frac{K_{f}}{2 r}
$$

The second-order condition is automatically satisfied since $c^{\prime \prime}(e)>0$. The optimal effort choice depends negatively on parameter $r$ from the quadratic effort-cost function and positively on the social preferences towards the firm. For $K_{f}=0$, the optimal level of effort is zero. In the case of $K_{f}<0$, the optimal effort is negative, which may be interpreted as intentionally harming (e.g., by acts of sabotage) the firm's objectives.

\subsection{Hypotheses}

Our primary hypotheses are grounded on assumptions that are more directly in line with the existing literature. However, our model is general enough to accommodate alternative hypotheses. In particular, our primary hypothesis is that workers' behavior is driven by reciprocity motives akin to the gift exchange hypothesis with respect to both the own wage and the other worker's wage, i.e., $\varphi>0 ; l>m>0$. Our primary assumption is also that workers feel both envy and compassion (as opposed to spite) when inequality exists, i.e., $-\alpha<-\beta<0$. Analytical derivations of the underlying predictions generated by the model can be found in the Online Appendix, Section B.1.4.

The first set of hypotheses concerns how workers react to the bonus payment, regardless of inequality concerns:

- Hypothesis $1 a$ (Gift exchange): Workers increase their effort in response to a bonus payment. Alternatively:

- Hypothesis $1 b$ (Contentment): Workers decrease their effort in response to a bonus payment.

The comparison between the Double Bonus condition and the Control condition provides a clean test of the first set of hypotheses because inequality is absent by construction. The Double Bonus condition is arguably the condition in which the perceived kindness of the firm should be at its highest.

The second and third hypotheses concern how inequality affects the effort of the worker not receiving the bonus and receiving the bonus, respectively. In general, aversion against horizontal pay inequality should lead to lower perceived kindness of the 
firm in single-bonus treatments, ceteris paribus. A disadvantaged worker will only increase effort if the satisfaction for the other worker's payoffs exceeds envy in its impact on the perceived kindness of the firm. This assumption is equivalent to $\varphi m>\alpha_{T}$, where $T$ is the index for the treatment condition. On the other hand, an advantaged worker will increase effort as long as the gift exchange component outweighs the effect of compassion. From the perspective of our model parameters, this corresponds to $\varphi_{1} l>\beta_{T}$. Conversely, if the advantaged worker is motivated by status-seeking (or spite), then she will attach positive utility to earning more than the other worker, as $\beta_{T}<0$. Effort increases more for the advantaged worker than for the disadvantaged worker under the assumptions that own payoffs have a more substantial weight than others' payoffs $(l>m>0)$ and that envy is a stronger psychological motivation than compassion $(\alpha>\beta)$.

- Hypothesis 2 (Envy): Aversion against disadvantageous horizontal pay inequality leads to negative effects on bonus nonrecipients' effort because of envious feelings $(\alpha>0)$. Accordingly, nonrecipients productivity should drop in single-bonus treatments compared to the Control condition.

- Hypothesis $3 a$ (Compassion): Compassion leads to bonus recipients to decrease their output in comparison with the Double Bonus condition $(\beta>0)$.

- Hypothesis $3 b$ (Status seeking/Spite): Status-seeking leads to bonus recipients to increase their output compared to the Double Bonus condition $(\beta<0)$.

The fourth hypothesis concerns the effect of the fairness of the source of inequality on effort. According to the discussion in Section 2, we posit the following:

- Hypothesis 4 a (Fairness Perception): The Productivity treatment and the Needs treatment are perceived as fairer than the Arbitrary treatment, because a reason is provided for the bonus allocation in the former but not in the latter.

- Hypothesis $4 b$ (Fairness Relevance): The higher the perceived fairness, the higher is the effort. In particular, the effort by both bonus recipients and nonrecipients should be higher in the Productivity treatment than in the Arbitrary treatment. Likewise, effort should be higher in the Needs treatment than in the Arbitrary treatment. $^{11}$

\section{Results}

We report the general patterns of the experiment results in Section 4.1. Section 4.2 provides the econometric analysis and the calibration of the utility function parameters. Section 4.3 analyzes perceptions of treatment fairness and their impact on productivity.

\footnotetext{
${ }^{11}$ Our research is exploratory as to whether productivity is higher or the same in the Productivity treatment compared to the Needs treatment.
} 
Section 4.4 performs robustness checks of the main results.

\subsection{Descriptive results}

Table 1 consolidates productivity within the morning and afternoon sessions, thus providing an overview of average productivity during the pre- and post-treatment phases. We use the number of typed characters per hour as our primary outcome measure because it provides the most precise measurement of individual effort. In Section 4.4, we analyze the robustness of our results to using alternative outcome measures. Overall, the average number of typed characters per hour increased from roughly 971 during the morning session to about 1057 entries per hour during the afternoon session, a statistically significant increase (Wilcoxon matched-pairs signed-rank test: $\mathrm{p}<0.001$, $\mathrm{N}=236$ ). Since reemployment concerns were ruled out by design (see Sections 2 and 5), and since we observe a significant productivity increase in the Control condition, learning must have played a role in such a productivity increase.

Figure 1 plots hourly productivity broken down by treatment and recipient status (bonus recipient vs. nonrecipient). A visual inspection of Figure 1 and Table 1 reveals little variability in productivity during the morning shift. Indeed, non-parametric tests fail to reject the null hypothesis of equal productivity (Kruskal-Wallis rank test: $\mathrm{p}=$ $0.750, \mathrm{~N}=236$ ) across the five treatment conditions at the level of worker pairs in the morning sessions. This result suggests that our treatment manipulation, as intended, was exogenous to workers' inherent ability. ${ }^{12}$ We cannot reject the null hypothesis of equal productivity between bonus recipients and nonrecipients in the afternoon session (Wilcoxon rank-sum test: $\mathrm{p}=0.409, \mathrm{~N}=236$ ). Furthermore, we can neither reject the null that productivity was the same in the afternoon session across the eight treatment conditions (Kruskall-Wallis rank test: $\mathrm{p}=0.582, \mathrm{~N}=236$ ), nor can we reject the null between the five conditions at the level of worker pairs (Kruskall-Wallis rank test: $\mathrm{p}=$ 0.713, $\mathrm{N}=236$ ). Thus, on average, the payment of bonuses apparently failed to induce higher productivity in the afternoon session.

\footnotetext{
${ }^{12}$ In the Online Appendix Table B.1, we further show that treatment conditions are balanced with respect to several observable characteristics.
} 
Figure 1: Hourly Data: Typed Characters
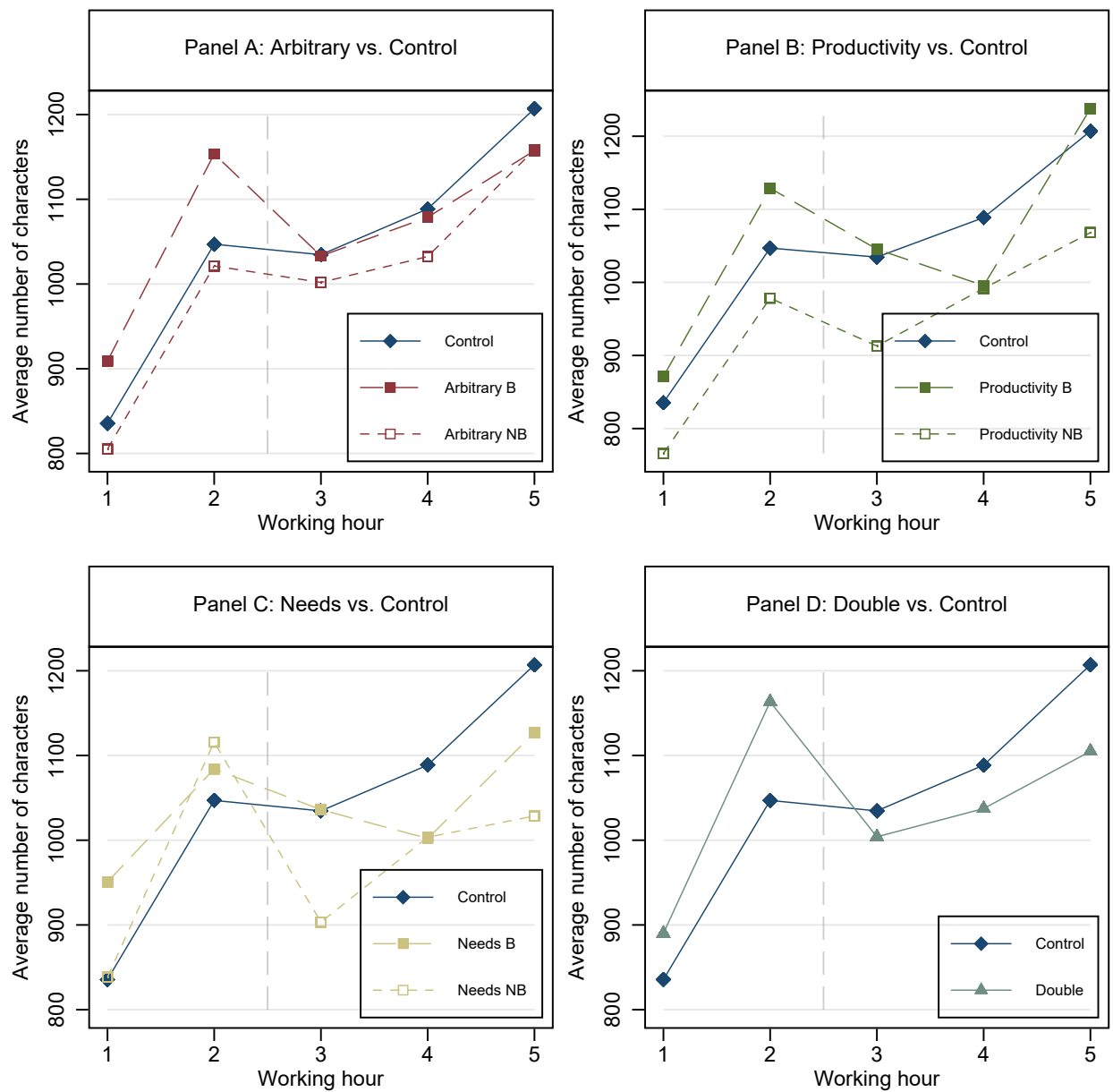

Note: The average number of typed characters is plotted for the five hours of the experiment for each treatment condition. The Control condition is plotted in every graph for reasons of comparison. If our assistants could not track hourly data for one hour due to technical reasons, they assigned the output count to the next hour. This practice leads to virtual productivity peaks. Due to this, the above figure shows "smoothed" data in which the average productivity of both hours was assigned to each of the hours in these cases. The figure looks qualitatively identical when plotting only observations for which the output was recorded for every single hour. 
Table 1: Average Number of Characters per Hour by Session

\begin{tabular}{lccccc}
\hline Condition & Morning & Afternoon & Diff. & p-value & Obs. \\
\hline \hline Pooled & 971.53 & 1057.40 & 85.87 & $<0.01$ & 236 \\
& $(274.44)$ & $(285.14)$ & $(201.70)$ & & \\
Control & 941.26 & 1110.10 & 168.85 & $<0.01$ & 39 \\
& $(235.46)$ & $(262.94)$ & $(217.12)$ & & \\
Double & 1026.71 & 1048.78 & 22.07 & 0.39 & 26 \\
& $(269.02)$ & $(329.50)$ & $(134.94)$ & & \\
Arbitrary B & 1031.29 & 1089.83 & 58.54 & 0.10 & 29 \\
& $(299.82)$ & $(313.31)$ & $(208.69)$ & & \\
Arbitrary NB & 913.22 & 1064.33 & 151.11 & $<0.01$ & 27 \\
& $(289.30)$ & $(302.57)$ & $(166.39)$ & & \\
Productivity B & 1000.11 & 1092.95 & 92.83 & $<0.01$ & 31 \\
& $(263.54)$ & $(232.64)$ & $(163.02)$ & & \\
Productivity NB & 872.20 & 990.92 & 118.72 & $<0.01$ & 28 \\
& $(226.72)$ & $(298.51)$ & $(202.11)$ & & \\
Needs B & 1017.47 & 1055.05 & 37.58 & 0.07 & 29 \\
& $(369.39)$ & $(320.66)$ & $(260.78)$ & & \\
Needs NB & 977.13 & 978.48 & 1.35 & 0.79 & 27 \\
& $(208.02)$ & $(219.65)$ & $(171.80)$ & & \\
\hline
\end{tabular}

Notes: Standard deviations in parentheses. p-values from Wilcoxon twosided sign-rank tests. B (NB) indicates bonus recipients (nonrecipients). 
Most of the previous experimental literature found a productivity burst after receiving the bonus, which may fade away with time (see Section 1). However, we find the contrary in our experiment. While productivity increases sizably within both the two-hour morning session (pre-treatment) and the three-hour afternoon session (posttreatment), productivity in the third hour is always lower than in the second hour (see Figure 1). Moreover, this finding holds in every treatment condition and the Control condition. ${ }^{13}$

\subsection{Econometric analysis and parameter calibration}

Because all workers have experienced the same working conditions during the morning session, differences in the changes of productivity from the morning to the afternoon session across treatments can be causally attributed to the treatment variation. Therefore, we base our analysis of treatment effects on the following difference-in-difference regression model:

$$
\begin{aligned}
y_{i t}=b_{0} & +\mu_{i}+b_{1}(\text { Double } \times a)+\sum_{T} b_{2_{T}} \cdot\left(\text { Advantaged }_{T} \times a\right) \\
& +\sum_{T} b_{3_{T}}\left(\text { Disadvantaged }_{T} \times a\right)+\gamma \cdot a+\epsilon_{i t}
\end{aligned}
$$

$y_{i t}$ denotes the outcome measure of worker $i$ in session $t$. The constant $b_{0}$ captures the average outcome per hour in the morning session $(t=1)$. Individual fixed effects $\mu_{i}$ control for individual heterogeneity in time-invariant characteristics, e.g. typing skills or the ability to concentrate, which may affect productivity. The indicator variable $a$ equals one if the observation is from the post-intervention $(t=2)$ period in the afternoon. We allow for the error term $\epsilon_{i t}$ to be clustered at the worker pair level at which we administered the treatments (Abadie et al., 2017). The interactions Double $\times a$,

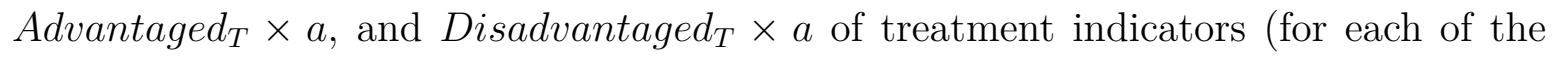
single-bonus treatments) with the post-intervention indicator deliver our estimated coefficients of interest. They capture the differences across treatments in the productivity change between the morning and the afternoon session, relative to the Control condition. According to an F-test, individual fixed effects are highly significant $(\mathrm{p}<0.001$, F-test).

Table 2 presents the regression results. The first two columns display coefficients for the number of typed characters as the dependent variable. While we look at treatment conditions separately in the first and the third columns, single-bonus treatment

\footnotetext{
${ }^{13}$ Since a short lunch break took place between the second and third hour (see Section 2), part of the productivity drop in the third hour may be due to a physiological drop in concentration due to food digestion, which we could call a "siesta effect".
} 
Figure 2: Changes in Average Hourly Productivity across Treatment Conditions

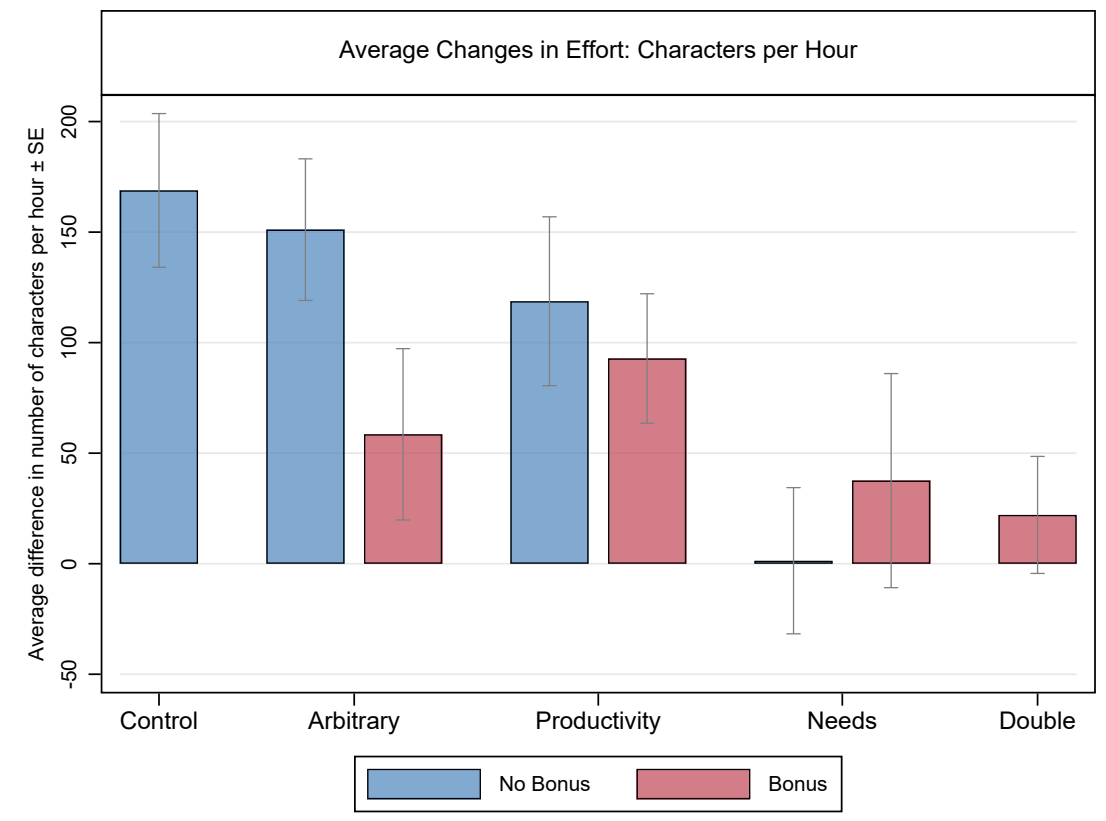

Note: The figure displays the mean difference and its standard error of the average hourly number of typed characters between the morning and afternoon session in the respective treatment conditions.

conditions are pooled in the second and fourth columns. Table 3 shows the calibrated parameters for the utility function developed in Section 3.1. A detailed explanation of the calibration exercise can be found in Section B.1.5 of the Online Appendix. The last two columns of Table 2 use the accuracy rate (share of correct entries relative to all entries), i.e., a measure of output quality, as the dependent variable. The results relative to quality are discussed in the robustness checks; see Section 4.4, where we also report results from multiple hypothesis testing adjustments. 
Table 2: Treatment Effects

\begin{tabular}{|c|c|c|c|c|}
\hline Dependent variable: & $\begin{array}{c}\text { Characters } \\
\text { (1) }\end{array}$ & $\begin{array}{c}\text { Characters } \\
(2)\end{array}$ & $\begin{array}{c}\text { Quality } \\
\text { (3) }\end{array}$ & $\begin{array}{c}\text { Quality } \\
\text { (4) }\end{array}$ \\
\hline Double $\times$ Afternoon & $\begin{array}{c}-146.8^{* * * *} \\
(43.00)\end{array}$ & $\begin{array}{c}-146.8^{* * * *} \\
(42.81)\end{array}$ & $\begin{array}{c}0.06 \\
(0.53)\end{array}$ & $\begin{array}{c}0.06 \\
(0.53)\end{array}$ \\
\hline Arbitrary NB $\times$ Afternoon & $\begin{array}{c}-17.74 \\
(49.47)\end{array}$ & & $\begin{array}{c}0.02 \\
(0.50)\end{array}$ & \\
\hline Arbitrary B $\times$ Afternoon & $\begin{array}{c}-110.3^{* *} \\
(54.05)\end{array}$ & & $\begin{array}{c}0.18 \\
(0.50)\end{array}$ & \\
\hline Productivity NB $\times$ Afternoon & $\begin{array}{l}-50.13 \\
(53.64)\end{array}$ & & $\begin{array}{c}0.02 \\
(0.87)\end{array}$ & \\
\hline Productivity $\mathrm{B} \times$ Afternoon & $\begin{array}{l}-76.01 \\
(47.81)\end{array}$ & & $\begin{array}{l}-0.81 \\
(0.51)\end{array}$ & \\
\hline Needs NB $\times$ Afternoon & $\begin{array}{c}-167.5^{* * *} \\
(50.14)\end{array}$ & & $\begin{array}{c}0.16 \\
(0.51)\end{array}$ & \\
\hline Needs B $\times$ Afternoon & $\begin{array}{c}-131.3^{* *} \\
(61.29)\end{array}$ & & $\begin{array}{c}0.02 \\
(0.56)\end{array}$ & \\
\hline Advantaged $\times$ Afternoon & & $\begin{array}{c}-105.2^{* *} \\
(43.95)\end{array}$ & & $\begin{array}{c}0.07 \\
(0.44)\end{array}$ \\
\hline Disadvantaged $\times$ Afternoon & & $\begin{array}{c}-78.11^{*} \\
(43.19)\end{array}$ & & $\begin{array}{l}-0.21 \\
(0.38)\end{array}$ \\
\hline Afternoon & $\begin{array}{c}168.8^{* * * *} \\
(37.88)\end{array}$ & $\begin{array}{c}168.8^{* * * * *} \\
(37.72)\end{array}$ & $\begin{array}{c}-0.70^{* *} \\
(0.29)\end{array}$ & $\begin{array}{c}-0.70^{* *} \\
(0.29)\end{array}$ \\
\hline Constant & $\begin{array}{c}971.5^{* * * *} \\
(6.06)\end{array}$ & $\begin{array}{c}971.5^{* * * *} \\
(6.25)\end{array}$ & $\begin{array}{c}98.01^{* * * *} \\
(0.08)\end{array}$ & $\begin{array}{c}98.01^{* * * * *} \\
(0.08)\end{array}$ \\
\hline No. Individuals & 236 & 236 & 236 & 236 \\
\hline No. Clusters & 126 & 126 & 126 & 126 \\
\hline \multicolumn{5}{|l|}{ Hypothesis tests (p-values) } \\
\hline Double $=$ Arbitary B & $\mathrm{p}=0.405$ & & $\mathrm{p}=0.834$ & \\
\hline Double $=$ Productivity $\mathrm{B}$ & $\mathrm{p}=0.049$ & & $\mathrm{p}=0.160$ & \\
\hline Double $=$ Needs B & $\mathrm{p}=0.767$ & & $\mathrm{p}=0.958$ & \\
\hline Double $=$ Advantaged & & $\mathrm{p}=0.173$ & & $\mathrm{p}=0.596$ \\
\hline Arbitrary B = Productivity B & $\mathrm{p}=0.479$ & & $\mathrm{p}=0.094$ & \\
\hline Arbitrary B $=$ Needs B & $\mathrm{p}=0.735$ & & $\mathrm{p}=0.799$ & \\
\hline Needs $B=$ Productivity $B$ & $\mathrm{p}=0.328$ & & $\mathrm{p}=0.194$ & \\
\hline Arbitrary NB = Productivity NB & $\mathrm{p}=0.514$ & & $\mathrm{p}=0.998$ & \\
\hline Arbitary NB $=$ Needs NB & $\mathrm{p}=0.001$ & & $\mathrm{p}=0.819$ & \\
\hline Needs NB $=$ Productivity NB & $\mathrm{p}=0.021$ & & $\mathrm{p}=0.885$ & \\
\hline
\end{tabular}

Notes: This table shows fixed effects regression results. The dependent variable in the first two columns is the average of characters entered per hour. The dependent variable in the remaining two columns is the share of correct entries relative to all entries. Standard errors in parentheses clustered at session level. ${ }^{* * * *} \mathrm{p}<0.001,{ }^{* * *} \mathrm{p}<0.01,{ }^{* *} \mathrm{p}<0.05$, $* \mathrm{p}<0.1$. Hypothesis tests are Wald tests of the null hypotheses that the changes in the dependent variable are equal in the contrasted conditions. Advantaged (Disadvantaged) refers to the pooled bonus recipients (nonrecipients) in single-bonus treatment conditions. 
The cleanest way to test for behavior compatible with the gift exchange hypothesis (Hypothesis 1) is to compare the Control condition with the Double Bonus condition because this comparison is not confounded with the introduction of earnings inequality between the two workers. We find that workers in the Double Bonus condition significantly reduced effort in response to a bonus relative to the Control condition (-15 percent of the morning session average, -146.8 characters per hour, $\mathrm{p}=0.001$ ). The estimated parameter $\varphi$, capturing the willingness to reciprocate a wage increase in (1) and (2), equals -11.7 and is significantly lower than $0(\mathrm{p}<0.001)$, pointing to a contentment effect rather than a gift exchange effect (see Section 3.1). Bonus recipients, on average, decreased productivity from the morning to the afternoon session relative to the Control condition pooling the three single-bonus conditions, confirming the prevalence of a contentment effect (-10.8 percent $^{14}$, -105.2 characters per hour, $\mathrm{p}=0.018$ ). We conclude:

- Result 1: Productivity in the Double Bonus condition decreased by roughly 15 percent in response to the wage bonus, reaching statistical significance at the 1 percent level. This result is consistent with a contentment effect (Hypothesis 1b) rather than a gift exchange effect (Hypothesis 1a).

To test Hypotheses 2 and Hypothesis 3 about the impact of earnings inequality on effort, we contrast productivity changes among bonus recipients (nonrecipients) in single-bonus treatments relative to the productivity change of workers in the Double Bonus (Control) condition. As the monetary payoff is the same in these treatment conditions, differences in productivity changes must be attributed to the payoff differential relative to the other worker. Consistently with Hypothesis 2, the calibration of the envy parameter $\alpha$ yields a positive sign pooling the single-bonus treatments, albeit not significantly different from zero.

To be seen as an explorative exercise as it is not part of our hypotheses laid out in the previous section, we also check whether the treatments inducing pay inequality affect effort relative to the relevant benchmark condition. Nonrecipients in the Arbitrary and Productivity treatments do not reveal statistically significant differences in their output change relative to the Control condition (-1.8 percent and -5.2 percent, -17.7 and -50.1 characters per hour, $\mathrm{p}=0.721$ and $\mathrm{p}=0.352$, respectively). On the contrary, nonrecipients in the Needs treatment strongly reduced effort relative to the Control condition (-17.2 percent, -167.5 characters per hour, $\mathrm{p}=0.001) .{ }^{15}$ As for advantageous

\footnotetext{
${ }^{14} \mathrm{We}$ express the productivity change in percentage terms of the morning session average (971.5 characters per hour).

${ }^{15}$ As a further robustness check, we compared the output change among nonrecipients in the Productivity treatment to those workers in the Control condition who were less productive than their coworker in the morning, leaving conclusion unchanged (-62 characters per hour, $\mathrm{p}=0.8$, rank-sum test).
} 
pay inequality, contrary to our primary Hypothesis 3a, we do not find negative effects on productivity. Output per hour increased among bonus recipients relative to the Double Bonus condition, the calibrated parameter $\beta$ equaling -3.33 pooling the single-bonus treatments. However, this difference is not significantly different from zero $(+4.3$ percent, 41.6 characters per hour, $\mathrm{p}=0.173)$. The sign is negative within each treatment, being significantly different from 0 only in the Productivity treatment $(+7.3$ percent, +70.8 characters per hour, $\mathrm{p}=0.049$, Wald test $)$, but not in the Needs $(+1.6$ percent, +15.5 characters per hour, $\mathrm{p}=0.767)$ nor the Arbitrary treatment $(+3.8$ percent, +36.5 characters per hour, $\mathrm{p}=0.405)$. This result is consistent with Hypothesis $3 \mathrm{~b}$ of status-seeking motivations rather than compassion (see Section 3.1). We conclude:

- Result 2: Disadvantageous pay inequality tended to yield a significantly negative effect on productivity, consistently with Hypothesis 2, although this was statistically significant (at the 1 percent level) only in the Needs treatment.

- Result 3: Advantageous pay inequality tended to yield a significantly positive effect on productivity, consistently with Hypothesis 3b of status-seeking behavior (rather than compassion). However, this was statistically significant (at the 5 percent level) only in the Productivity treatment. 
Table 3: Calibrated Model Parameters

\begin{tabular}{ccccc}
\hline & Pooled & Arbitrary & Productivity & Needs \\
\hline \hline$\varphi$ & -11.74 & -11.74 & -11.74 & -11.74 \\
& $(3.43)^{* * * *}$ & $(3.44)^{* * * *}$ & $(3.44)^{* * * *}$ & $(3.44)^{* * * *}$ \\
$\beta_{T}$ & -3.33 & -2.92 & -5.66 & -1.24 \\
& $(2.42)$ & $(3.47)$ & $(2.84)^{* *}$ & $(4.18)$ \\
$\alpha_{T}$ & 6.25 & 1.42 & 4.01 & 13.40 \\
& $(3.45)$ & $(3.96)$ & $(4.29)$ & $(4.01)^{* * *}$ \\
\hline Hypothesis tests & \multicolumn{2}{c}{$\beta_{T}$} & \multicolumn{2}{c}{$\alpha_{T}$} \\
\hline Arbitrary = Productivity & \multicolumn{2}{c}{$\mathrm{p}=0.479$} & $\mathrm{p}=0.514$ \\
Arbitrary = Needs & $\mathrm{p}=0.735$ & $\mathrm{p}=0.001$ \\
Needs = Productivity & $\mathrm{p}=0.328$ & $\mathrm{p}=0.021$
\end{tabular}

Notes: The table contains calibrated structural parameters for each single-bonus treatment and pooled treatments. We assume $\mathrm{m}=0$, i.e. gift exchange or contentment effects are only dependent on own income for the calibration. Parameter of the quadratic cost function is set to $\mathrm{r}=1$. **** indicates $\mathrm{p}<0.001$, *** indicates $\mathrm{p}<0.01$, ** indicates $\mathrm{p}$ $<0.05$ and $*$ indicates $\mathrm{p}<0.1$ of significant difference to zero. 
Figure 3: Post-experimental Evaluation

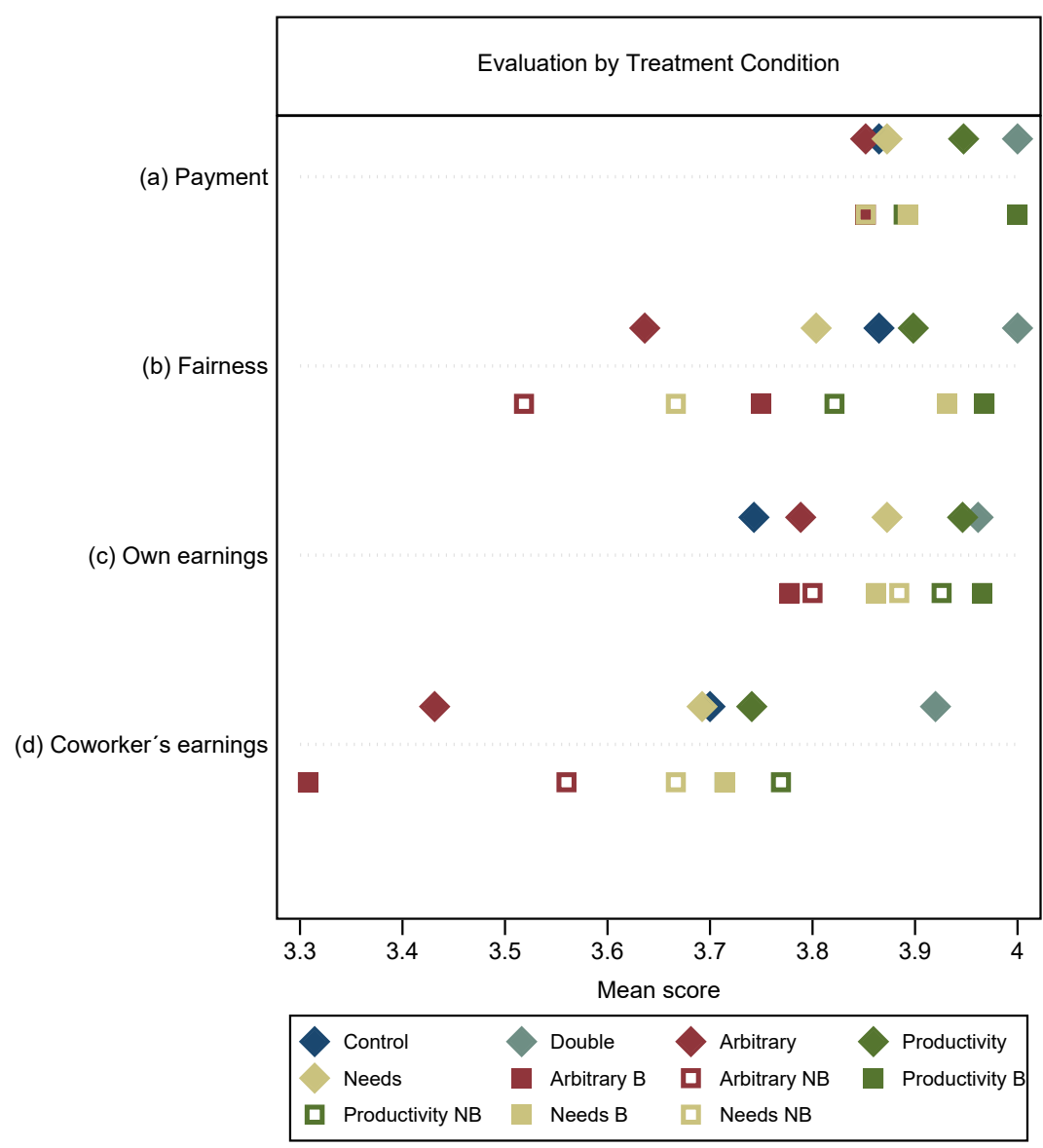

Note: This figure shows the average answer score from the post-experimental survey by treatment condition. Arbitrary, Productivity, and Needs are averages over the respective conditions of recipients and nonrecipients. Answers could range between 1 "absolutely disagree" and 4 "absolutely agree" with respect to the following statements: (a) The payment I received was adequate. (b) The treatment of the two persons hired was fair. (c) The earnings I received in the second part of the day were deserved. (d) The earnings my coworker received in the second part of the day were deserved.

\subsection{Impact of procedural fairness}

In addition to the results on productivity in the previous sections, questions from the post-experiment questionnaire allow analyzing the perception of pay fairness across treatments delivering additional insights. More precisely, we asked workers to rate (a) the adequacy of payment, (b) the fairness of how workers had been treated, and whether (c) their own earnings or (d) the coworker's earnings in the afternoon session were deserved. Answers could range from 1 (absolute disagreement) to 4 (absolute agreement). Figure 3 shows mean answer scores by treatment condition. Section B.1.7 in the Online Appendix reports an analysis of differences between treatments from OLS regressions. 
Most workers perceived the payment as adequate, with little difference between treatments (see Online Appendix Table B.6). ${ }^{16}$ Remarkably, all Double Bonus workers reported being treated fair, constituting the condition with the highest perceived fairness. Nonrecipients in the Arbitrary treatment stand out for reporting the lowest average score for the overall fairness of how the workers were treated. Their evaluation score is marginally significantly lower than under the Control condition $(\mathrm{p}=0.074$, Wald test) and the Double Bonus condition ( $\mathrm{p}=0.006$, Wald test). It is also at the margin of being significantly lower relative to nonrecipients under the Productivity treatment ( $\mathrm{p}=0.12$, Wald test; Table B.6, column 2). Considering bonus recipients and nonrecipients together, reported fairness in the Arbitrary treatment is significantly lower than in the Productivity treatment $(\mathrm{p}=0.025$, Wald test) and the Double Bonus condition ( $\mathrm{p}=0.001$, Wald-test; Table B.5, column 2).

Perception of deservedness of their own earnings in the afternoon session was highest for bonus recipients in the Productivity and the Double Bonus condition, reaching (marginal) statistical significance relative to the Control condition $(\mathrm{p}=0.074$ and $\mathrm{p}$ $=0.081$, respectively Wald tests; Table B.6, column 4). The most sizable differences across treatments are observed when participants rated coworkers' earnings deservedness. Again, workers in the Arbitrary treatments expressed the lowest scores. Nonrecipients in the Arbitrary treatment report a lower score than workers in the Double bonus condition ( $\mathrm{p}=0.050$, Wald test). Bonus recipients' score was even lower than nonrecipients' score within the Arbitrary treatment and was lower than in the Control condition ( $\mathrm{p}=0.110$, Wald test), the Double Bonus condition ( $\mathrm{p}=0.003$, Wald test), and compared to bonus recipients in the Productivity treatment $(\mathrm{p}=0.071$, Wald test) and the Needs treatment $(\mathrm{p}=0.063$, Wald test). Bonus recipients and nonrecipients in the Needs treatment rated the deservedness of coworker's earnings lower than workers under the Double bonus condition ( $\mathrm{p}=0.046$ and $\mathrm{p}=0.048$, respectively, Wald tests).

However, these mild differences in self-reported fairness perceptions in both Arbitrary treatment conditions failed to result in significant behavioral responses, i.e., productivity differences. More precisely, we detect no difference between Productivity and Arbitrary treatments in the calibrated parameters relative to inequality aversion neither for bonus recipients $(\mathrm{p}=0.479$, Wald test) nor for nonrecipients $(\mathrm{p}=0.514$, Wald test) (see Table 3). Hence, our data do not yield robust support for Hypothesis 4b. Bonus recipients' output increased more in the Productivity treatment than the Needs treatment, although the difference is insignificant at conventional levels $(+5.7$ percent, +55.3 characters per hour, $\mathrm{p}=0.328$, Wald test). Contrary to our expectations, nonrecipients' output dropped in the Needs treatment significantly relative to

\footnotetext{
${ }^{16}$ Nonrecipients in the Arbitrary and the Needs treatment report the lowest scores, in case of the latter significantly lower than in the Double bonus condition $(\mathrm{p}=0.036$, Wald test $)$.
} 
both the Arbitrary (-15.4 percent, -149.8 characters per hour, $\mathrm{p}=0.001$, Wald test) and the Productivity (-12.1 percent, -117.4 characters per hour, $\mathrm{p}=0.021$, Wald test) treatment. Thus, we conclude:

- Result 4: Hypothesis 4a concerning fairness perceptions receives some support, albeit at often statistically insignificant levels. The Arbitrary treatment is generally perceived as less fair than the Productivity treatment, although differences reach statistical significance at the $5 \%$ level only considering bonus recipients and nonrecipients jointly. However, such differences in perception do not lead to any significant change in productivity in the Arbitrary treatment compared to the other single-bonus conditions, thus contradicting Hypothesis 4b. Surprisingly, we observe a considerable and statistically significant drop in productivity by nonrecipients in the Needs treatment. However, this drop is not reflected in fairness or deservedness ratings.

\subsection{Robustness checks}

In principle, workers' behavioral reactions to the treatments are not restricted to the quantity margin of their output but possibly extend to their quality. In other words, workers may, consciously or unconsciously, adjust the precision of their work to either repay a gift from the employer or, adversely, punish them. In particular, workers dissatisfied with their treatment may try to "sabotage" the firm, keeping the number of typed characters per hour relatively unchanged but willingly introducing mistakes in their output. This behavior would result in mistakes of various kinds, such as spelling mistakes, omissions, entry swaps, in the output returned by the worker. Therefore, we investigated treatment effects on the quality margin, i.e., on the share of correct entries relative to all entries, in the afternoon session compared to the morning session in the third and fourth columns of Table 2.

Our analysis fails to find any appreciable quality changes between the afternoon and morning sessions, neither in the aggregate nor across treatments. The share of correct entries relative to all entries is roughly 98 percent across all conditions, only slightly varying between conditions. Consequently, a non-parametric test of the null of equal changes in output quality between the morning and afternoon sessions across treatment groups cannot be rejected ( $\mathrm{p}=0.570, \mathrm{~N}=236$, Kruskal-Wallis test). Similarly, results are not qualitatively impacted by evaluating the number of correct entries instead of typed characters as the outcome variable, providing a composite measure of the output quantity and quality. Both findings indicate that the treatments do not significantly impact the quality dimension of work. Thus, we can also rule out that the contentment effect was driven by working with less speed but higher precision. 
Furthermore, the results documented in the previous sections are unaffected by several robustness checks. Pairwise treatment comparisons with Wilcoxon rank-sum tests, as shown in Table B.8 in the Online Appendix, yield identical conclusions to the regression analysis. We do not find any sign of a trend ${ }^{17}$ in the output changes from the morning to the afternoon session over the 126 days of data collection, which speaks against the possibility of contagion effects among workers. Omitting outliers by the method of Tukey's fences does not have a significant impact on our results. Results are also robust to excluding fifteen observations where a confederate acted as the second worker if a recruited (co-)worker did not show up (see Section 2 and Table B.7). In the Online Appendix, we plot empirical cumulative distribution functions (ECDFs) (see Section B.1.2). The ECDFs show that the contentment effect is not only apparent in the differences in means, but also when we consider the full distributions, thus revealing a broad behavioral pattern. The ECDF corresponding to the productivity change in the Double Bonus condition is clearly shifted to the left compared to the ECDF of the Control condition. Workers who received a bonus in the single-bonus treatments also showed productivity changes more similar to those in the Double Bonus condition, consistent with the presence of a contentment effect among them. On the contrary, the productivity changes of nonrecipients in single-bonus treatments are more similar to those of the Control condition, except for the nonrecipients in the Needs treatment whose productivity relatively decreased.

As our experiment involves contrasting several conditions with each other or the relevant control condition, a further robustness check is to control the familywise error rate by adjusting for multiple hypothesis testing (List, Shaikh and Xu, 2019). We shortly refer to the p-values based on the step-down procedure by Romano and Wolf (2005) concerning our hypotheses from Section 3.2 in the main text. For the adjusted p-values of ancillary results and those utilizing the conservative Bonferroni-Holm correction, we refer to the Appendix Section B.1.3. Our main result concerning the contentment effect remains highly significant (Romano-Wolf $\mathrm{p}=0.003$, see Table B.2). Similarly, the negative effect of disadvantageous pay inequality on effort remains marginally significant (Romano-Wolf $\mathrm{p}=0.088$, pooling nonrecipients from single-bonus treatments). This negative effect of disadvantageous pay inequality also holds concerning the most vigorous reaction when the bonus was assigned to the other worker in the Needs treatment (Romano-Wolf $\mathrm{p}=0.015$, Table B.4). Furthermore, the negative effect on effort among nonrecipients in the Needs treatment remains statistically significant relative to nonrecipients in the Arbitrary (Romano-Wolf $\mathrm{p}=0.012$, Table B.3) and Productivity treatments (Romano-Wolf $\mathrm{p}=0.073$ ). On the other hand, the supplementary result

\footnotetext{
${ }^{17}$ The $\mathrm{p}$-value of the time trend is $\mathrm{p}=0.6$ in an OLS regression with the output change as dependent variable.
} 
concerning the effort increase among bonus recipients in the Productivity treatment relative to the Double bonus condition is no longer statistically significant (Romano-Wolf $\mathrm{p}=0.175)$.

\section{Discussion}

Experimental results are typically assessed in terms of internal and external validity. Esteves-Sorenson (2018) considers eight possible confounds, primarily affecting the internal validity in gift exchange studies, whose relevance for our study we discuss in the following. First, peer effects may create idiosyncratic effects on outcomes. Such effects were minimized in our setting because workers were prevented from interacting and communicating at any stage of the work session (see Section 2). Second, EstevesSorenson (2018) discusses concerns that within-subject pay manipulation may lead agents to inflate their effort after receiving a bonus because they want to avoid experiencing disutility from being perceived as selfish, a factor that may be confounded with reciprocity. However, this factor seems to be irrelevant in our naturalistic setting as we observe treated participants displaying, if anything, selfish behavior in comparison to non-treated participants, as the former reduce their productivity after receiving the bonus relative to the Control condition. Moreover, as we study a natural field experiment (Harrison and List, 2004; Al-Ubaydli and List, 2017), participants ignore being part of an experiment and are not motivated to comply with the researcher's perceived goals. Third, we also do not believe that insufficient wage raises played a part in our experiment. The bonus equaled $33 \%$ of the advertised wage rate, and this is at least on par with other experiments that found a gift exchange effect (Bellemare and Shearer, 2009; Cohn, Fehr and Goette, 2015; Gilchrist, Luca and Malhotra, 2016).

Fourth, effort ceiling effects were likely absent in our experiment because the workers demonstrated that higher productivity was possible. Productivity peaked in the last hour of the experiment and the three-hour afternoon session gave ample time to workers to reciprocate the bonus. Fifth, fatigue effects most likely also played a minor role. Productivity was particularly low after the lunch break offering time to recover but, on average, increased in all treatment conditions and the Control condition over time (see Figure 1). Sixth, we cannot rule out that the relatively high wage set in the Control condition, relative to the standard wage rate, led to the selection of workers abler than usual (Esteves-Sorenson, 2018). Nevertheless, the base wage was arguably appropriate, taking into account the commuting time and travel costs for Bogotá residents. Moreover, its value was decided after the pilot experiment's indication that a lower wage may have led to significant attrition. Moreover, the random assignment of workers into treatment minimizes the chance that results based on differences between 
treatments are due to imbalances in workers' abilities (see Section 4.1 for the discussion of treatment exogeneity concerning pre-intervention productivity).

Seventh, as for reemployment concerns, we followed the best practice from other experiments and repeatedly ruled out, starting from the recruitment stage, that there would be any possibility for the worker to be re-employed in the future. The one-time nature is crucial because the worker's effort reaction has to be the product of a desire to reciprocate kind actions rather than an attempt to build up a fruitful long-term relationship for an internally valid test of the gift exchange hypothesis (Al-Ubaydli and List, 2019). We cannot, of course, exclude that participants did not fully believe, or take into account, this announcement. If this were the case, it would be unclear why reemployment concerns should differently affect the Control and treatment conditions. Relatedly, nonrecipients in single-bonus treatments may have felt motivated to increase their effort levels if they had thought that not receiving the bonus was a signal for lower reemployment chances. Likewise, non-bonus recipients may have imagined that another bonus would have been paid at the end of the working day. However, the announcement (see the instructions) clarified what final earnings would be to rule out such motivations, e.g., from performance incentives. If these motivations were nonetheless at play, they should have presumably led nonrecipients in the Productivity treatment to raise their effort because the bonus depended directly on workers' output. However, productivity by nonrecipients was not higher in the Productivity treatment than in the Arbitrary treatment in the afternoon session relative to the morning session (see Figure 2), suggesting that this factor did not play a significant role. More generally, productivity by nonrecipients in single-bonus treatments was in every case lower than in the Control condition in the afternoon session relative to the morning session. This finding suggests that effects due to reemployment concerns or the desire to receive a hypothetical second bonus were largely irrelevant.

The eighth and final point of concern Esteves-Sorenson (2018) is that of small samples. Our study had an overall larger sample size than other experiments detecting gift exchange in natural experimental labor markets (Gneezy and List, 2006; Kube, Maréchal and Puppe, 2012). Hence, we had adequate power to detect the existence of reciprocity effects. However, one may argue that we were still under-powered to capture differences between the various single-bonus treatments' effects, particularly between the Productivity and the Arbitrary treatments. We observe minimal differences between Arbitrary and Productivity treatments. The observed effect sizes amount to a Cohen's d of roughly 0.18 comparing both treatments for bonus recipients and nonrecipients (see Table 1). This result makes us doubtful that we are incurring a Type-II error. Only a larger sample size could fully ascertain this aspect. ${ }^{18}$

\footnotetext{
${ }^{18}$ Laboratory studies comparing analogous treatments in Dictator Games find effect sizes in the range
} 
An additional concern is that the strength of a reciprocal response may depend on whether the value of effort for the employer is emphasized to the workers, as discussed in parts of the gift exchange literature (Englmaier and Leider, 2020). We cannot exclude the relevance of this concern to our study. However, we deliberately chose not to emphasize the importance of the work for the employer as we believed this could have had a detrimental effect on the naturalness of the setting. Nevertheless, even if the value of effort for the employer in performing the relatively tedious data entry task may not have been clear to the workers, this fact alone cannot explain why we observe a significant decrease in effort in response to the bonus. This remark is critical since emphasizing the importance of effort is far from standard in the gift exchange literature (Gneezy and List, 2006; Kube, Maréchal and Puppe, 2012). However, it might well be that emphasizing the importance of effort might have rendered the emergence of a contentment effect less likely, e.g., by inducing sympathy for the employer, increasing the likelihood for reciprocal behavior.

In terms of our results' generalizability, we support List (2020), who points out, "all results are externally valid to some setting, and no result will be externally valid to all settings." We follow the request in List (2020) to report on the SANS conditions, i.e., selection, attrition, naturalness, and scaling. First, in terms of selection, recruited workers (through advertisements at the university and social networks) are predominantly young and have a student or unemployment background. At first glance, the, on average, young age of participants can be seen as a potential limitation of our study. Although a substantial portion of participants was not the usual convenience sample of university students, we acknowledge significant differences across different age groups. Research comparing experimental student samples and nationally representative samples (Bellemare and Kröger, 2007; Cappelen et al., 2015) generally find that the former tend to behave more selfishly than other groups in the population. If that was the case, we might expect different patterns of reciprocity from workers of older age. However, we believe that the sample composition should not be seen as a valid threat to external validity but instead reflects the target population. That is to say, recruiting workers for a short-term opportunity of unskilled work in a naturalistic setting will always lead to

of $\mathrm{d}=0.4$, requiring a massive sample size of roughly 100 observations in each contrasted condition to ensure an a priori power of 80 percent, given alpha $=0.05$. Our initial assumption was that the effect size in our sample would have been considerably larger than $\mathrm{d}=0.4$ for two reasons. First, we oriented at the famous gift exchange study by Gneezy and List (2006) who found an effect size for the gift exchange effect of roughly $\mathrm{d}=0.65$ in the fundraising task, for which 26 participants in each contrasted treatment conditions suffice to reach an a-priori power of 80 percent with an alpha of 0.05. Second, we were convinced that the Arbitrary treatment would have caused a more significant negative effect than treatments where assignment to roles is determined by an unbiased "fair" lottery (Bolton, Brandts and Ockenfels, 2005; Grimalda, Kar and Proto, 2016). We also believed that effects would have been more prominent in a natural setting than in a laboratory. However, from an ex-post perspective, our assumptions did not turn out to be the case on either account. 
a sample leaning to the younger and, by its very nature, unemployed or student parts of the population (see OECD, 2002; ter Weel, 2018). This feature arguably reflects for whom such a work opportunity is economically reasonable and similarly impacted the sample composition of virtually every previous investigation of the gift exchange hypothesis in temporary work environments (Gneezy and List, 2006; Hennig-Schmidt, Sadrieh and Rockenbach, 2010; Kube, Maréchal and Puppe, 2012). Thus, they resemble the natural characteristics of the underlying population applying for unskilled temporary work opportunities (OECD, 2002) rendering the sample composition realistic for the target setting (List, 2020).

As conducting elaborate field experiments always carry the risk of attrition, this is the second of the SANS conditions. As reported in Section 2 above, one out of the two recruited (co-)workers for each session did not show up in fifteen cases. Hence, fifteen out of 236 workers in our sample were unawarely working with a confederate. However, dropping those observations from the sample does not influence our results, as shown in the robustness checks (Section 4.4). We have no further information on whether the workers who did not appear at the appointment were intrinsically different in their motivations or incentives from the workers in the target population, which, in any case, should only cover workers who show up at the appointed time.

A crucial consideration regarding the naturalness condition is whether the experiment places subjects on an artificial or natural margin when making their choices (List, 2020). We are convinced that workers faced definite situational similarities to real-life temporary work opportunities as we used a natural field experiment that fulfills both conditions posed by Harrison and List (2004). First, workers were unaware of taking part in an experiment. Second, the recruitment process, task, and work environment were natural since they would be the same if the work had been done devoid of any research purposes, i.e., without treatments and observation of workers' behavior. In such a setting, people are generally less restricted in their behavior, favoring the emergence of unforeseen results (List and Rasul, 2011). We believe that most of our design elements are standard components of real-life labor contracts, albeit to a minor degree in terms of the Needs treatment. Bonus payments are widespread in labor markets worldwide, and linking them to productivity is common (Bewley, 1999). Admittedly, it would be extravagant for a company to offer a selective bonus without giving any justification for it, as we do in the Arbitrary treatment. Nevertheless, it is also arguably the case that most workers, when prone to a self-serving bias, may fail to recognize the legitimacy of the justification given by a manager for assigning the bonus to another worker. Thus workers may consider the selective bonus tantamount to being arbitrary (Bewley, 1999). Selective payments based on needs are rare in real-life labor market contracts. As argued in Section 2, this treatment's purpose was to investigate reactions 
to an allocation principle having psychological salience and being policy-relevant. A possible explanation for the substantial productivity decrease among nonrecipients in the Needs treatment could precisely be that bonus assignment due to social status is not considered by workers to be a fair or appropriate reason at the workplace (Kahneman, Knetsch and Thaler, 1986).

Regarding the naturalness of the task, data entry is typical for a broad range of clerical work. It demands only widespread skills and allows for exact measurement of productivity, making it the most popular task in the gift exchange literature leveraging natural field experiments (Gneezy and List, 2006; Kube, Maréchal and Puppe, 2012; DellaVigna et al., 2022). It offers the obvious advantage of being a task without specific skill requirements and delivers a standardized measure of effort that can be compared across different settings.

Furthermore, our naturalistic setting resembles a work environment in which workers provide individual effort, whereas, in many jobs, outcomes result from a collective effort by several coworkers. Since such efforts cannot be singled out easily, adding this dimension into our experiment would have introduced undesirable confounds. In addition, short-term temporary work opportunities often rely on individual effort to increase flexibility and avoid the necessity of building harmonic teams for the employer. Another feature of our study than can be seen as a potential limitation, albeit a necessary design choice to ensure internal validity, is the focus on short-term employment (see also point seven in the discussion above). Hence, we cannot evaluate the long-term effects of the treatments. Nevertheless, the relevance of casual employment and temporary work contracts is extreme in countries with higher informality rates and is also rapidly increasing in developed countries (International Labour Organization, 2016; OECD, 2019). Finally, as our research does not belong to the programmatic studies speaking to policymakers, the scaling condition is not applicable (List, 2020).

A further relevant aspect that deserves particular attention is the relevance of cultural effects in determining our results, whose discussion we see as an extension to reporting on the SANS conditions (List, 2020). Several studies have unveiled the relevance of culture for economic outcomes (Guiso, Sapienza and Zingales, 2006; Bandiera and Fischer, 2013). A natural concern is that it is unclear whether our findings would replicate in a different cultural context, particularly in high-income Western societies where previous field tests of the gift exchange hypothesis were performed (Gneezy and List, 2006; Kube, Maréchal and Puppe, 2012; Cohn, Fehr and Goette, 2015). We believe that two points are in order on this aspect. First of all, Henrich, Heine and Norenzayan (2010) and Henrich (2020) have forcefully argued that a disproportionate amount of research has been carried out in Western societies and that people from these societies are somewhat peculiar compared to other societies. Suppose economics, as a 
science, strives for developing universally valid notions. In that case, it should confront itself with cultural diversity and investigate the extent to which principles of behavior are truly universal or culture-specific. Moreover, Western societies are probably the exception, rather than the norm, regarding cultural or psychological traits (Henrich, Heine and Norenzayan, 2010). Hence, even if a cultural peculiarity (as compared to rich Western countries) should partially drive our results, this should not discount their relevance. This argument is especially valid from the background that Colombia has a population of more than 50 million people, which itself arguably constitutes a highly relevant entity to study.

Secondly, the growing body of literature on cross-cultural analysis enables us to gauge the impact of the cultural traits specific to Colombia. For example, the mapping of social preferences in the Global Preference Survey (GPS) (Falk et al., 2018) shows that people from Colombia have an average score on positive reciprocity (the variable particularly relevant in a gift exchange situation) comparable to Northern Americans and Europeans. On the grounds of this study, one may expect that the results found in Colombia would be generalizable to Western countries. If one digs deeper into cultural traits, though, some differences emerge. According to the six-dimension model of national culture by Hofstede, Hofstede and Minkov (2010), Colombia ranks as one of the most collectivistic countries worldwide within the collectivist-individualism dimension (see also Hofstede Insights, 2020). Colombia also tops the rankings for power distance, i.e., the degree to which "the less powerful members of institutions and organizations within a country expect and accept an unequal distribution of power" (Hofstede, Hofstede and Minkov, 2010). On the other hand, North-Western countries typically rank high in individualism and low in power distance. One may conjecture that collectivism - when workers perceive themselves as belonging to a different group than the entrepreneur - and power distance contribute to workers perceiving themselves as socially distant from the entrepreneur. If that is the case, workers may not perceive the payment of a bonus as a "kind" act that warrants gratitude. Alternatively, they may expect that the entrepreneur will not construe their extra effort as an act of kindness. As a result, they may not feel the need, or the moral obligation, to reciprocate a change in the wage rate, even if such a change goes to their advantage. In societies where power distance and collectivism are not dominant cultural traits, employees may engage (or perceive to) with entrepreneurs on relatively equal standing. They may then have more psychological incentives to perform positive reciprocity. In another natural experiment spanning different cultural areas, Bandiera, Dahlstrand-Rudin and Fischer (2020) found that employees from most collectivistic countries respond less to wage incentives in contracts offered by companies. Our findings, to some extent, mirror their results. However, the incentivization scheme in Bandiera, Dahlstrand-Rudin and 
Fischer (2020) relies on standard economic incentives rather than positive reciprocity. Overall, such results suggest that monetary incentives and bonus payments intended to elicit an intrinsic desire to pay good actions back in kind may be construed differently across different cultures at a basic level.

\section{Concluding remarks}

The main result of this paper has been the finding of significant productivity decreases in response to a bonus payment in the context of a one-day labor contract involving two workers. A decrease among bonus recipients occurs in all treatments considered, but the effect is more significant when both workers are bonus recipients. The result contradicts the gift exchange hypothesis (Akerlof, 1982) and is consistent with what we labeled a contentment effect: The worker interprets the bonus payment as a signal that the entrepreneur is satisfied with the worker's performance, with no moral obligation to reciprocate. Hence, our finding suggests that workers' behavior in this natural field experiment follows the logic assumed in traditional economic models (e.g., Lazear, 2000), viewing workers as behaving opportunistically (List and Rasul, 2011).

We also find that social comparison effects only played a minor role: workers who received a bonus as sole beneficiaries tended to increase productivity, albeit statistically insignificantly, compared to the Double Bonus condition, pointing to status-seeking preferences (Frank, 1985). Consistent with the observation that relative wages matter when evaluating whether the treatment was fair (Bewley, 1999), a bonus may create a perception of higher recognition when the wage of the non-rewarded serves as a reference point (Kahneman and Tversky, 1979). Hence, this reaction partially offsets the contentment effect. Nonrecipients significantly reduced productivity only in the Needs treatment. In general, workers' behavior responded only marginally to different justifications for pay inequality. More research is needed to ascertain the extent to which these results would hold across different age and cultural groups. Given that we only observed one data point for the base wage and the bonus payment, further research should also investigate the possible existence of a "ceiling effect" in reciprocity and a diminishing sensitivity to kindness.

Overall, our findings echo Bewley's (1999) insight that introducing pay inequality in the wage structure of a company may backfire. However, we have uncovered a new channel whereby this effect manifests itself, which has not to do with work morale but instead to workers' lack of responsiveness to the "gift" offered by the firm. 


\section{References}

Abadie, Alberto, Susan Athey, Guido Imbens, and Jeffrey Wooldridge. 2017. "When Should You Adjust Standard Errors for Clustering?"

Abbink, Klaus, and Abdolkarim Sadrieh. 2009. "The pleasure of being nasty." Economics Letters, 105(3): 306-308. Abbink, Klaus, and Benedikt Herrmann. 2011. "The Moral Costs of Nastiness." Economic Inquiry, 49(2): 631-633.

Adams, J. Stacy. 1963. "Toward an understanding of inequity." Journal of abnormal psychology, 67: 422-436.

Akerlof, George A. 1982. "Labor Contracts as Partial Gift Exchange." The Quarterly Journal of Economics, 97(4): 543-569.

Akerlof, George A., and Janet L. Yellen. 1990. "The Fair Wage-Effort Hypothesis and Unemployment." The Quarterly Journal of Economics, 105(2): 255-283.

Alesina, Alberto, and Paola Giuliano. 2011. "Preferences for Redistribution." In Handbook of social economics. Vol. 1 of Handbooks in economics, , ed. Alberto Bisin, Jess Benhabib and Matthew O. Jackson, 93-131. Amsterdam and London and Boston:Elsevier/North-Holland.

Almås, Ingvild, Alexander W. Cappelen, and Bertil Tungodden. 2020. "Cutthroat Capitalism versus Cuddly Socialism: Are Americans More Meritocratic and Efficiency-Seeking than Scandinavians?" Journal of Political Economy, 128(5): 1753-1788.

Al-Ubaydli, Omar, and John A. List. 2017. "Field Experiments in Markets." In Handbook of economic field experiments. Vol. 1 of Handbooks in economics, , ed. Abhijit V. Banerjee and Esther Duflo, 271-307. Amsterdam and Oxford:North-Holland an imprint of Elsevier.

Al-Ubaydli, Omar, and John A. List. 2019. "How natural field experiments have enhanced our understanding of unemployment." Nature human behaviour, 3(1): 33-39.

Al-Ubaydli, Omar, Steffen Andersen, Uri Gneezy, and John A. List. 2015. "Carrots that look like sticks: Toward an understanding of multitasking incentive schemes." Southern Economic Journal, 140212121118009.

Ariely, Dan, Emir Kamenica, and Dražen Prelec. 2008. "Man's search for meaning: The case of Legos." Journal of Economic Behavior 83 Organization, 67(3-4): 671-677.

Azariadis, Costas. 1975. "Implicit Contracts and Underemployment Equilibria." Journal of Political Economy, 83(6): 1183-1202.

Babcock, Linda, and George Loewenstein. 1997. "Explaining Bargaining Impasse: The Role of Self-Serving Biases." Journal of Economic Perspectives, 11(1): 109-126.

Bandiera, Oriana, Amanda Dahlstrand-Rudin, and Greg Fischer. 2020. "Incentives and Culture: Evidence from a Multi-Country Field Experiment." Working Paper.

Bandiera, Oriana, and Greg Fischer. 2013. "Can "good" HR practices be exported? Evidence from a field experiment in Ghana." Working Paper.

Becker, Gary S. 1974. "A Theory of Social Interactions." Journal of Political Economy, 82(6): 1063-1093.

Bellemare, Charles, and Bruce Shearer. 2009. "Gift giving and worker productivity: Evidence from a firm-level experiment." Games and Economic Behavior, 67(1): 233-244.

Bellemare, Charles, and Sabine Kröger. 2007. "On representative social capital." European Economic Review, 51(1): 183-202.

Bénabou, Roland, and Jean Tirole. 2006. "Incentives and Prosocial Behavior." American Economic Review, 96(5): 1652-1678.

Bewley, Truman Fassett. 1999. Why wages don't fall during a recession. Cambridge, Mass:Harvard University Press.

Bogliacino, Francesco, Laura Jiménez Lozano, and Daniel Reyes. 2018. "Socioeconomic stratification and stereotyping: Lab-in-the-field evidence from Colombia." International Review of Economics, 65(1): 77-118.

Bolton, Gary E., and Axel Ockenfels. 2000. "ERC: A Theory of Equity, Reciprocity, and Competition." American Economic Review, 90(1): 166-193.

Bolton, Gary E., Jordi Brandts, and Axel Ockenfels. 2005. "Fair Procedures: Evidence from Games Involving Lotteries." The Economic Journal, 115(506): 1054-1076.

Bracha, Anat, Uri Gneezy, and George Loewenstein. 2015. "Relative Pay and Labor Supply." Journal of Labor Economics, 33(2): 297-315.

Bradler, Christiane, Susanne Neckermann, and Arne Jonas Warnke. 2019. "Incentivizing Creativity: A LargeScale Experiment with Performance Bonuses and Gifts." Journal of Labor Economics, 37(3): 793-851.

Breza, Emily, Supreet Kaur, and Yogita Shamdasani. 2018. "The Morale Effects of Pay Inequality*." The Quarterly Journal of Economics, 133(2): 611-663.

Cappelen, Alexander W., Astri Drange Hole, Erik Ø. Sørensen, and Bertil Tungodden. 2007. "The Pluralism of Fairness Ideals: An Experimental Approach." American Economic Review, 97(3): 818-827.

Cappelen, Alexander W., Knut Nygaard, Erik Ø. Sørensen, and Bertil Tungodden. 2015. "Social Preferences in the Lab: A Comparison of Students and a Representative Population." The Scandinavian Journal of Economics, 
117(4): 1306-1326.

Charness, G., and M. Rabin. 2002. "Understanding Social Preferences with Simple Tests." The Quarterly Journal of Economics, 117(3): 817-869.

Charness, Gary. 2004. "Attribution and Reciprocity in an Experimental Labor Market." Journal of Labor Economics, 22(3): 665-688.

Charness, Gary, Guillaume R. Frechette, and John H. Kagel. 2004. "How Robust is Laboratory Gift Exchange?" Experimental Economics, 7(2): 189-205.

Charness, Gary, Luca Rigotti, and Aldo Rustichini. 2007. "Individual Behavior and Group Membership." American Economic Review, 97(4): 1340-1352.

Clarke, Damian. 2021. "RWOLF2: Stata module to calculate Romano-Wolf stepdown p-values for multiple hypothesis testing."

Cohn, Alain, Ernst Fehr, and Lorenz Goette. 2015. "Fair Wages and Effort Provision: Combining Evidence from a Choice Experiment and a Field Experiment." Management Science, 61(8): 1777-1794.

Cohn, Alain, Ernst Fehr, Benedikt Herrmann, and Frédéric Schneider. 2014. "Social comparison and effort provision: Evidence from a field experiment." Journal of the European Economic Association, 12(4): 877-898.

Cox, James C., Daniel Friedman, and Steven Gjerstad. 2007. "A tractable model of reciprocity and fairness." Games and Economic Behavior, 59(1): 17-45.

Cullen, Zoë, and Ricardo Perez-Truglia. 2022. "How Much Does Your Boss Make? The Effects of Salary Comparisons." Journal of Political Economy, 130(3): 766-822.

Deffains, Bruno, Romain Espinosa, and Christian Thöni. 2016. "Political self-serving bias and redistribution." Journal of Public Economics, 134(3): 67-74.

DellaVigna, Stefano, John A. List, Ulrike Malmendier, and Gautam Rao. 2022. "Estimating Social Preferences and Gift Exchange at Work." American Economic Review, 112(3): 1038-1074.

Dufwenberg, Martin, and Georg Kirchsteiger. 2004. "A theory of sequential reciprocity." Games and Economic Behavior, 47(2): 268-298.

Durante, Ruben, Louis Putterman, and Joël van der Weele. 2014. "Preferences for Redistribution and Perception of Fairness: An Experimental Study." Journal of the European Economic Association, 12(4): 1059-1086.

Englmaier, Florian, and Stephen Leider. 2020. "Managerial Payoff and Gift-Exchange in the Field." Review of Industrial Organization, 56(2): 259-280.

Esteves-Sorenson, Constança. 2018. "Gift Exchange in the Workplace: Addressing the Conflicting Evidence with a Careful Test." Management Science, 64(9): 4365-4388.

Falk, Armin, and Andrea Ichino. 2006. "Clean Evidence on Peer Effects." Journal of Labor Economics, 24(1): 39-57.

Falk, Armin, and Urs Fischbacher. 2006. "A theory of reciprocity." Games and Economic Behavior, 54(2): 293-315.

Falk, Armin, Anke Becker, Thomas Dohmen, Benjamin Enke, David Huffman, and Uwe Sunde. 2018. "Global Evidence on Economic Preferences*." The Quarterly Journal of Economics, 133(4): 1645-1692.

Fehr, E., and K. M. Schmidt. 1999. "A Theory of Fairness, Competition, and Cooperation." The Quarterly Journal of Economics, 114(3): 817-868.

Fehr, E., G. Kirchsteiger, and A. Riedl. 1993. "Does Fairness Prevent Market Clearing? An Experimental Investigation." The Quarterly Journal of Economics, 108(2): 437-459.

Fehr, Ernst, and Armin Falk. 1999. "Wage Rigidity in a Competitive Incomplete Contract Market." Journal of Political Economy, 107(1): 106-134.

Fehr, Ernst, and Simon Gächter. 1998. "Reciprocity and economics: The economic implications of Homo Reciprocans." European Economic Review, 42(3-5): 845-859.

Fehr, Ernst, and Simon Gächter. 2000. "Fairness and Retaliation: The Economics of Reciprocity." Journal of Economic Perspectives, 14(3): 159-182.

Fehr, Ernst, and Urs Fischbacher. 2004. "Third-party punishment and social norms." Evolution and Human Behavior, 25(2): 63-87.

Fehr, Ernst, Daniela Glätzle-Rützler, and Matthias Sutter. 2013. "The development of egalitarianism, altruism, spite and parochialism in childhood and adolescence." European Economic Review, 64(1): 369-383.

Fehr, Ernst, Erich Kirchler, Andreas Weichbold, and Simon Gächter. 1998. "When Social Norms Overpower Competition: Gift Exchange in Experimental Labor Markets." Journal of Labor Economics, 16(2): 324-351.

Fehr, Ernst, Lorenz Goette, and Christian Zehnder. 2009. "A Behavioral Account of the Labor Market: The Role of Fairness Concerns." Annual Review of Economics, 1(1): 355-384.

Frank, Robert H. 1985. Choosing the right pond: Human behavior and the quest for status. New York, NY:Oxford Univ. Press.

Gächter, Simon, and Christian Thöni. 2010. "Social comparison and performance: Experimental evidence on the fair wage-effort hypothesis." Journal of Economic Behavior $\&$ Organization, 76(3): 531-543. 
Gibbs, Michael, Susanne Neckermann, and Christoph Siemroth. 2017. "A Field Experiment in Motivating Employee Ideas." The Review of Economics and Statistics, 99(4): 577-590.

Gilchrist, Duncan S., Michael Luca, and Deepak Malhotra. 2016. "When $3+1>4$ : Gift Structure and Reciprocity in the Field." Management Science, 62(9): 2639-2650.

Gneezy, Uri, and John A. List. 2006. "Putting Behavioral Economics to Work: Testing for Gift Exchange in Labor Markets Using Field Experiments." Econometrica, 74(5): 1365-1384.

Goldszmidt, Ariel, John List, Robert Metcalfe, Ian Muir, V. Kerry Smith, and Jenny Wang. 2020. "The Value of Time in the United States: Estimates from Nationwide Natural Field Experiments."

Grimalda, Gianluca, Anirban Kar, and Eugenio Proto. 2016. "Procedural fairness in lotteries assigning initial roles in a dynamic setting." Experimental Economics, 19(4): 819-841.

Guiso, Luigi, Paola Sapienza, and Luigi Zingales. 2006. "Does Culture Affect Economic Outcomes?" Journal of Economic Perspectives, 20(2): 23-48.

Hagenlocher, Michael, Eric Delmelle, Irene Casas, and Stefan Kienberger. 2013. "Assessing socioeconomic vulnerability to dengue fever in Cali, Colombia: Statistical vs expert-based modeling." International journal of health geographics, 12: 36 .

Harrison, Glenn W., and John A. List. 2004. "Field Experiments." Journal of Economic Literature, 42(4): 10091055.

Heffetz, Ori, and Robert H. Frank. 2011. "Chapter 3 - Preferences for Status: Evidence and Economic Implications." In Handbook of social economics. Handbooks in economics, , ed. Alberto Bisin, Jess Benhabib and Matthew O. Jackson. Amsterdam and London and Boston:Elsevier/North-Holland.

Hennig-Schmidt, Heike, Abdolkarim Sadrieh, and Bettina Rockenbach. 2010. "In Search of Workers' Real Effort Reciprocity-a Field and a Laboratory Experiment." Journal of the European Economic Association, 8(4): 817837.

Henrich, Joseph. 2020. The WEIRDest People in the World: How the West Became Psychologically Peculiar and Particularly Prosperous. [S.I.]:Farrar, Straus and Giroux.

Henrich, Joseph, Steven J. Heine, and Ara Norenzayan. 2010. "The weirdest people in the world?" The Behavioral and brain sciences, 33(2-3): 61-83; discussion 83-135.

Hofstede, Geert, Gert Jan Hofstede, and Michael Minkov. 2010. Cultures and organizations: Software of the mind ; intercultural cooperation and its importance for survival. . Rev. and expanded 3. ed. ed., New York:McGrawHill.

Hofstede Insights. 2020. "Country comparisons."

Holz, Justin, John List, Alejandro Zentner, Marvin Cardoza, and Joaquin Zentner. 2020. "The \$100 Million Nudge: Increasing Tax Compliance of Businesses and the Self-Employed using a Natural Field Experiment."

International Labour Organization. 2016. Non-standard employment around the world: Understanding challenges, shaping prospects. Geneva:International Labour Office.

Kahneman, Daniel, and Amos Tversky. 1979. "Prospect Theory: An Analysis of Decision under Risk." Econometrica, 47(2): 263.

Kahneman, Daniel, Jack L. Knetsch, and Richard H. Thaler. 1986. "Fairness as a Constraint on Profit Seeking: Entitlements in the Market." The American Economic Review, 76(4): 728-741.

Katz, Lawrence F. 1986. "Efficiency Wage Theories: A Partial Evaluation." NBER Macroeconomics Annual, 1: 235.

Konow, James. 2000. "Fair Shares: Accountability and Cognitive Dissonance in Allocation Decisions." American Economic Review, 90(4): 1072-1092.

Konow, James. 2003. "Which Is the Fairest One of All? A Positive Analysis of Justice Theories." Journal of Economic Literature, 41(4): 1188-1239.

Kosfeld, Michael, and Susanne Neckermann. 2011. "Getting More Work for Nothing? Symbolic Awards and Worker Performance." American Economic Journal: Microeconomics, 3(3): 86-99.

Krawczyk, Michał. 2010. "A glimpse through the veil of ignorance: Equality of opportunity and support for redistribution." Journal of Public Economics, 94(1-2): 131-141.

Krawczyk, Michal Wiktor. 2011. "A model of procedural and distributive fairness." Theory and Decision, 70(1): 111128.

Kube, Sebastian, Michel André Maréchal, and Clemens Puppe. 2012. "The Currency of Reciprocity: Gift Exchange in the Workplace." American Economic Review, 102(4): 1644-1662.

Kube, Sebastian, Michel André Maréchal, and Clemens Puppe. 2013. "Do wage cuts damage work morale? Evidence from a natural field experiment." Journal of the European Economic Association, 11(4): 853-870.

Lazear, Edward P. 2000. "Performance Pay and Productivity." American Economic Review, 90(5): 1346-1361.

Lindbeck, A., and Dennis Snower. 1988. "Cooperation, Harassment, and Involuntary Unemployment: An InsiderOutsider Approach." American Economic Review, 78(1): 167-188. 
List, John. 2020. "Non est Disputandum de Generalizability? A Glimpse into The External Validity Trial."

List, John A., and Imran Rasul. 2011. "Field Experiments in Labor Economics." In Handbook of labor economics. Vol. 4 of Handbooks in economics, , ed. David E. Card and Orley Ashenfelter, 103-228. Amsterdam and New York and New York, N.Y., U.S.A:North-Holland.

List, John A., Azeem M. Shaikh, and Yang Xu. 2019. "Multiple hypothesis testing in experimental economics." Experimental Economics, 22(4): 773-793.

Loewenstein, George F., Leigh Thompson, and Max H. Bazerman. 1989. "Social utility and decision making in interpersonal contexts." Journal of Personality and Social Psychology, 57(3): 426-441.

Martinsson, Peter, Clara Villegas-Palacio, and Conny Wollbrant. 2015. "Cooperation and social classes: Evidence from Colombia." Social Choice and Welfare, 45(4): 829-848.

Mezulis, Amy H., Lyn Y. Abramson, Janet S. Hyde, and Benjamin L. Hankin. 2004. "Is there a universal positivity bias in attributions? A meta-analytic review of individual, developmental, and cultural differences in the self-serving attributional bias." Psychological bulletin, 130(5): 711-747.

Miller, Dale T., and Michael Ross. 1975. "Self-serving biases in the attribution of causality: Fact or fiction?" Psychological bulletin, 82(2): 213-225.

Nicklisch, Andreas, and Fabian Paetzel. 2020. "Need-Based Justice and Distribution Procedures: The Perspective of Economics." In Need-Based Distributive Justice. , ed. Stefan Traub and Bernhard Kittel, 161-190. Cham:Springer International Publishing.

OECD. 2002. "Taking the Measure of Temporary Employment." In OECD Employment Outlook 2002. , ed. OECD, 127-185. OECD.

OECD, ed. 2019. OECD employment outlook 2019: The future of work. Paris:OECD Publishing.

Rabin, Matthew. 1993. "Incorporating Fairness into Game Theory and Economics." American Economic Review, 83(5): 1281-1302.

Romano, Joseph P., and Michael Wolf. 2005. "Stepwise Multiple Testing as Formalized Data Snooping." Econometrica, 73(4): 1237-1282.

Schurter, Karl, and Bart J. Wilson. 2009. "Justice and Fairness in the Dictator Game." Southern Economic Journal, 76(1): 130-145.

ter Weel, Bas. 2018. "The Rise of Temporary Work in Europe." De Economist, 166(4): 397-401.

Trautmann, Stefan T. 2009. "A tractable model of process fairness under risk." Journal of Economic Psychology, 30(5): 803-813. 
A Appendix

Table A.1: Sample Characteristics

\begin{tabular}{lccccc}
\hline Variable & Obs & Mean & Std. Dev. & Min & Max \\
\hline \hline Age & 235 & 21.16 & 1.92 & 18 & 27 \\
Female & 234 & 0.54 & 0.50 & 0 & 1 \\
Married & 236 & 0.08 & 0.27 & 0 & 1 \\
Occupation & & & & & \\
Student & 236 & 0.83 & 0.38 & 0 & 1 \\
Unemployed & 236 & 0.10 & 0.30 & 0 & 1 \\
Other & 236 & 0.07 & 0.25 & 0 & 1 \\
Estratificación socioeconómica & & & & & \\
1 & 234 & 0.05 & 0.21 & 0 & 1 \\
2 & 234 & 0.38 & 0.49 & 0 & 1 \\
3 & 234 & 0.47 & 0.50 & 0 & 1 \\
4 & 234 & 0.09 & 0.28 & 0 & 1 \\
5 & 234 & 0.02 & 0.13 & 0 & 1 \\
6 & 234 & 0.00 & 0.07 & 0 & 1 \\
Education & & & & & \\
High school & 236 & 0.10 & 0.30 & 0 & 1 \\
Some college semester & 236 & 0.55 & 0.50 & 0 & 1 \\
Technical degree (Técnico) & 236 & 0.15 & 0.36 & 0 & 1 \\
University degree & 236 & 0.19 & 0.39 & 0 & 1 \\
\hline
\end{tabular}

Notes: Table shows summary statistics for the participants' characteristics. 


\title{
B Online Appendix (Supplementary Online Mate- rial)
}

\author{
Supplementary Online Material for \\ Kind or contented? An investigation of the gift exchange hypothesis in a natural field \\ experiment in Colombia \\ Francesco Bogliacino, Gianluca Grimalda, David Pipke
}

In Section B.1 of the Online Appendix, we provide additional analyses and more detailed derivations based on our theoretical model. Section B.2 contains the experiment instructions, the protocol, and the final questionnaire.

\section{B.1 Analyses and Derivations}

\section{B.1.1 Treatment Balance}

Table B.1: Balance Table

\begin{tabular}{lccccccc} 
& Control & Arbitrary & Productivity & Needs & Double & Total & F-test \\
\hline \hline Age & 21.711 & 20.446 & 21.288 & 21.321 & 21.269 & 21.162 & 0.008 \\
& $(2.205)$ & $(1.548)$ & $(1.894)$ & $(1.879)$ & $(2.070)$ & $(1.921)$ & \\
Female & 0.590 & 0.518 & 0.627 & 0.491 & 0.423 & 0.540 & 0.368 \\
& $(0.498)$ & $(0.504)$ & $(0.488)$ & $(0.505)$ & $(0.504)$ & $(0.499)$ & \\
Married & 0.128 & 0.054 & 0.085 & 0.071 & 0.077 & 0.081 & 0.818 \\
& $(0.339)$ & $(0.227)$ & $(0.281)$ & $(0.260)$ & $(0.272)$ & $(0.273)$ & \\
Estrato & 2.526 & 2.582 & 2.678 & 2.673 & 2.962 & 2.661 & 0.208 \\
& $(0.687)$ & $(0.896)$ & $(0.753)$ & $(0.840)$ & $(0.774)$ & $(0.805)$ & \\
Degree & 0.359 & 0.393 & 0.322 & 0.304 & 0.269 & 0.335 & 0.787 \\
& $(0.486)$ & $(0.493)$ & $(0.471)$ & $(0.464)$ & $(0.452)$ & $(0.473)$ & \\
\hline
\end{tabular}

Notes: Table displays background characteristics for each treatment condition at the level of worker pairs and the total sample. On average, workers are slightly younger in the Arbitrary treatment condition, significant according to an F-test, although the mean difference to the other conditions is 1.25 years at the maximum. "Degree" is a dummy for having an highereducation degree (Technical "Técnico" or University degree). The p-value we report in the last column is from a F-test of joint significance in a regression of background characteristic on treatment indicators. 


\section{B.1.2 Empirical distribution functions of productivity changes}

Figure B.1: ECDF: Arbitrary versus Reference Conditions

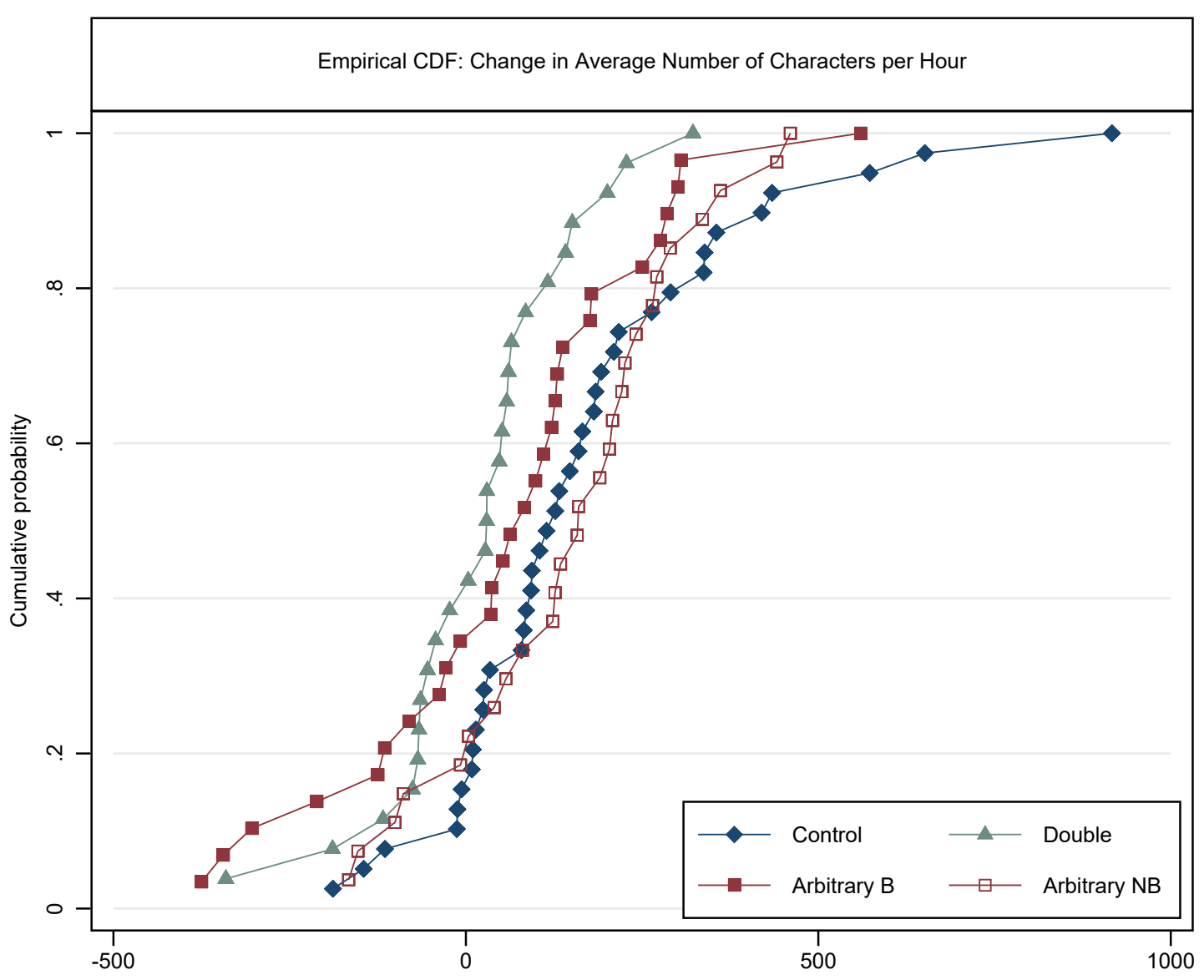

Note: This figure shows the empirical distribution function of productivity changes between the morning and the afternoon session (change in average output in characters per hour between sessions). The plotted conditions are indicated in the legend. 
Figure B.2: ECDF: Productivity versus Reference Conditions

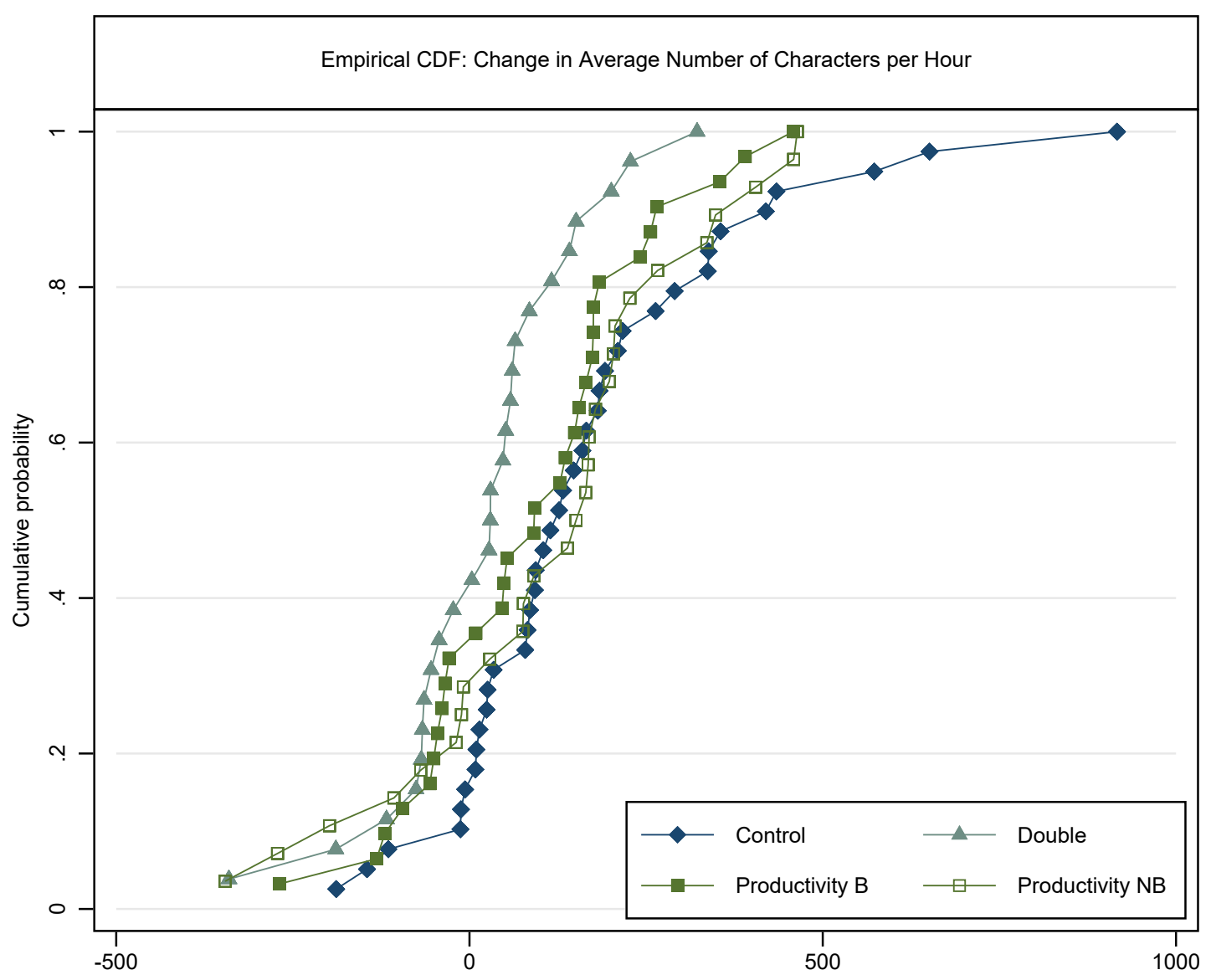

Note: This figure shows the empirical distribution function of productivity changes between the morning and the afternoon session (change in average output in characters per hour between sessions). The plotted conditions are indicated in the legend. 
Figure B.3: ECDF: Needs versus Reference Conditions

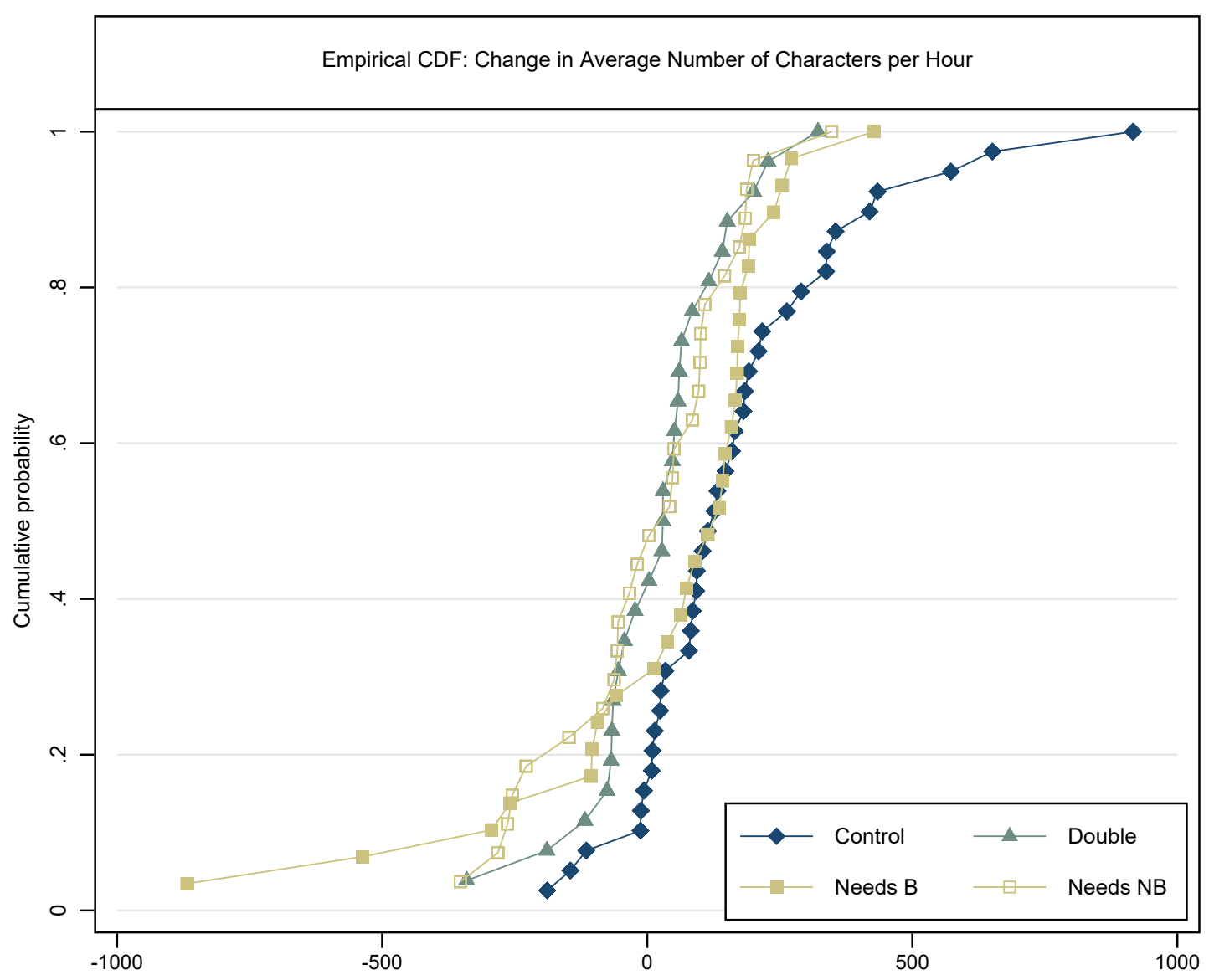

Note: This figure shows the empirical distribution function of productivity changes between the morning and the afternoon session (change in average output in characters per hour between sessions). The plotted conditions are indicated in the legend. 


\section{B.1.3 Multiple Hypothesis Testing Adjustments}

Because experiments often involve comparing outcomes across several treatment conditions with each other or relative to the relevant control condition, reporting p-values using methods controlling the familywise error rate should become the best practice in experimental work (List, Shaikh and $\mathrm{Xu}, 2019$ ). The following tables show unadjusted p-values, Romano-Wolf p-values using the step-down procedure (Romano and Wolf, 2005; Clarke, 2021), and the classical Bonferroni-Holm p-values.

Table B.2: p-values with Multiple Testing Adjustments: Main Results

\begin{tabular}{lcccc}
\hline & Differences & \multicolumn{3}{c}{ Multiple testing adjustment } \\
\cline { 3 - 5 } & $\begin{array}{c}\text { Unadjusted } \\
\text { p-values }\end{array}$ & $\begin{array}{c}\text { Romano-Wolf } \\
\text { p-values }\end{array}$ & $\begin{array}{c}\text { Bonferroni-Holm } \\
\text { p-values }\end{array}$ \\
\hline Double = Control & -146.8 & 0.001 & 0.003 & 0.003 \\
Disadvantaged = Control & -78.1 & 0.073 & 0.088 & 0.146 \\
Advantaged = Double & 105.2 & 0.173 & 0.131 & 0.173 \\
\hline
\end{tabular}

Notes: The table reports unadjusted and adjusted p-values from our main hypotheses. Differences refer to the estimates in column 2 of Table 2. Romano-Wolf p-values with 5000 bootstrapping replications. $\mathrm{k}=3$ is the number of unadjusted p-values under consideration. $k_{i}$ is the number of p-values among the $\mathrm{k} \mathrm{p}$-values at least as large as the unadjusted $p_{i}$. The Bonferroni-Holm pvalues are defined as $\min \left(1, k_{i} p_{i}\right)$. Romano-Wolf p-values calculated with the STATA package rwolf2 using the step-down procedure. 
Table B.3: p-values with Multiple Testing Adjustments: Different Justifications between Single-Bonus Treatments

\begin{tabular}{lcccc}
\hline & & \multicolumn{3}{c}{ Multiple testing adjustment } \\
\cline { 3 - 5 } & Differences & $\begin{array}{c}\text { Unadjusted } \\
\text { p-values }\end{array}$ & $\begin{array}{c}\text { Romano-Wolf } \\
\text { p-values }\end{array}$ & $\begin{array}{c}\text { Bonferroni-Holm } \\
\text { p-values }\end{array}$ \\
\hline Arbitary B = Productivity B & -34.3 & 0.479 & 0.791 & 1 \\
Arbitary B = Needs B & 21.0 & 0.735 & 0.791 & 0.735 \\
Productivity B = Needs B & 55.3 & 0.329 & 0.657 & 1 \\
Arbitary NB = Productivity NB & 32.4 & 0.515 & 0.791 & 1 \\
Arbitary NB = Needs NB & 149.8 & 0.001 & 0.012 & 0.008 \\
Productivity NB = Needs NB & 117.4 & 0.021 & 0.073 & 0.105 \\
\hline
\end{tabular}

Notes: The table reports unadjusted and adjusted p-values from comparing productivity changes between bonus recipients and nonrecipients across different justifications. Differences refer to the estimates in column 1 of Table 2. Romano-Wolf p-values with 5000 bootstrapping replications. $\mathrm{k}=6$ is the number of unadjusted p-values under consideration. $k_{i}$ is the number of $\mathrm{p}$-values among the $\mathrm{k} \mathrm{p}$-values at least as large as the unadjusted $p_{i}$. The Bonferroni-Holm p-values are defined as $\min \left(1, k_{i} p_{i}\right)$. Romano-Wolf p-values calculated with the STATA package rwolf2 using the step-down procedure. 
Table B.4: p-values with Multiple Testing Adjustments: Additional Results concerning Single-Bonus Treatments versus relevant Benchmark Conditions

\begin{tabular}{lcccc}
\hline & & \multicolumn{3}{c}{ Multiple testing adjustment } \\
\cline { 3 - 5 } & Differences & $\begin{array}{c}\text { Unadjusted } \\
\text { p-values }\end{array}$ & $\begin{array}{c}\text { Romano-Wolf } \\
\text { p-values }\end{array}$ & $\begin{array}{c}\text { Bonferroni-Holm } \\
\text { p-values }\end{array}$ \\
\hline Arbitrary NB = Control & -17.7 & 0.721 & 0.910 & 1 \\
Productivity NB = Control & -50.1 & 0.352 & 0.748 & 1 \\
Needs NB = Control & -167.5 & 0.001 & 0.015 & 0.007 \\
Arbitary B = Double & 36.5 & 0.405 & 0.748 & 1 \\
Productivity B = Double & 70.8 & 0.049 & 0.175 & 0.244 \\
Needs B = Double & 15.5 & 0.767 & 0.910 & 0.767 \\
\hline
\end{tabular}

Notes: The table reports unadjusted and adjusted p-values from contrasting single-bonus conditions to the relevant benchmark conditions. Differences refer to the estimates in column 1 of Table 2. Romano-Wolf p-values with 5000 bootstrapping replications. $\mathrm{k}=6$ is the number of unadjusted $\mathrm{p}$-values under consideration. $k_{i}$ is the number of $\mathrm{p}$-values among the $\mathrm{k} \mathrm{p}$-values at least as large as the unadjusted $p_{i}$. The Bonferroni-Holm p-values are defined as $\min \left(1, k_{i} p_{i}\right)$. Romano-Wolf pvalues calculated with the STATA package rwolf2 using the step-down procedure. 


\section{B.1.4 Calculation of effort predictions}

We examine optimal effort choices in reaction to possible payoff combinations which can arise in our setup. In the first period, no bonus is paid by the firm such that $w_{i}=w_{j}=w$ holds, i.e. there is no wage inequality. The optimal level of effort is equal to:

$$
\hat{e_{1}}=\frac{1}{2 r}\left[\kappa+\varphi(l+m)\left(w-w_{\text {norm }}\right)\right]
$$

The effort level in the first period must be equal across treatments. The second period differs across treatment conditions depending on whom received the bonus. In the Control condition, no worker receives the bonus in the second period. Nevertheless, learning or fatigue effects are possible. We therefore set the effort level in the second period to be equal to the sum of the first period effort and a random variable $\tilde{L}$. We assume $\tilde{L}$ to be normally distributed across individuals with mean $\mu_{L}$ and variance $\sigma_{L}^{2}$.

$$
e_{2_{\text {Control }}}=\hat{e_{1}}+\tilde{L}^{i}
$$

In the Double Bonus condition, both workers receive the bonus, hence the second term capturing pay inequality of equation (2) equals zero.

- If both workers receive a bonus $\left(w_{i}=w_{j}=w+B\right)$, the difference in the optimal effort between the second and first period must be equal to:

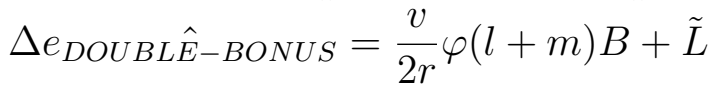

- The difference in optimal effort between the first and the second period for the worker receiving the bonus (whom we label as ADV)is:

$$
\Delta \hat{e}_{T}^{A D V}=\frac{1}{2 r}\left[\varphi\{l \cdot B\}+\left\{-\alpha_{T} \cdot B\right\}\right]+\tilde{L}
$$

where $T=\{P R O D U C T I V I T Y ; N E E D S ; A R B I T R A R Y\}$ are the three single-bonus treatment conditions.

- The difference in optimal effort between the first and the second period for the worker not receiving the bonus (whom we label as DIS):

$$
\Delta \hat{e}_{T}^{D I S}=\frac{1}{2 r}\left[\varphi\{m \cdot B\}+\left\{-\beta_{T} \cdot B\right\}\right]+\tilde{L}
$$

We can now examine how optimal effort responds to bonus payments in our model's framework, assuming $\tilde{L}>0$. First, in case of a situation in which both workers receive a bonus $B>0$, effort unambigously increases relative to the first period if $\varphi>0$ since

$$
\varphi_{1} \cdot(l+m) \cdot B+\tilde{L}>0
$$

In this situation of a "Double Bonus", the firm does not induce any wage inequality 
between the workers. The predicted behaviour by the model corresponds to the assumed reciprocating behaviour of paying back a kind action of the firm with kindness. If instead only one worker receives the bonus, the firm is no longer seen as unambigously kind in our proposed model. The effort of the benefitted worker increases relative to the first period in which payoffs were equal if

$$
\left\{\varphi l+\left(-\alpha_{T}\right)\right\} B+\tilde{L}>0
$$

holds. This corresponds to a situation where the appreciation of the gift received by worker i outweighs inequality aversion in the effect on the perceived kindness of the firm.

In case of $\alpha_{T}<0$, which corresponds to a preference for advantageous inequality under the respective justification $T$, effort may increase even more than under the Double Bonus if this preference is stronger than the weighted delight for the other worker:

$$
\varphi\{l \cdot B\}+\left(-\alpha_{T} \cdot B\right)>\varphi(l+m) B \Leftrightarrow\left(-\alpha_{T}\right)>\varphi_{1} \cdot m
$$

If instead the other worker receives the bonus, the disadvantaged worker's effort increases relative to the first period without payoff inequality if

$$
\begin{gathered}
\varphi\{m \cdot B\}+\left(-\beta_{T} \cdot B\right)>0 \\
\Longleftrightarrow \varphi \cdot m-\beta_{T}>0 \Leftrightarrow \varphi_{1} \cdot m>\beta_{T}
\end{gathered}
$$

holds. In words, the disadvantaged worker must be delighted strongly enough for the other worker who receives the bonus such that the total effect on the perceived kindness of the firm is still positive despite the inequality in payoffs. Comparing both cases of inequality, the increase in effort from period 1 to period 2 is smaller in the case when the worker is disadvantaged than when the worker is benefitted by the bonus assignment if

$$
\begin{aligned}
\varphi \cdot l \cdot B+\left(-\alpha_{T} \cdot B\right) & >\varphi \cdot m \cdot B+\left(-\beta_{T} \cdot B\right) \\
& \Leftrightarrow \varphi \cdot l+\left(-\alpha_{T}\right)>\varphi_{1} \cdot m+\left(-\beta_{T}\right) \Leftrightarrow \varphi(l-m)>\alpha_{T}-\beta_{T}
\end{aligned}
$$

, which holds for a parameterization in which $l>m$ (higher weight for own than coworker's earnings in gift exchange part) and $\beta>\alpha$ (envy is stronger than compassion) hold, assuming $\varphi>0$. Predicted effort changes vary with the parameters $l$ and $m$ defining interdependent preferences. For reasons of clarity, we assume $\varphi>0$ in the 
following discussion. First, we take a look at the case of a purely selfish worker i, i.e. for which $m=0$, i.e. a purely selfish worker does not care about the other worker's payoffs in the gift exchange part. In this case, worker i's effort changes by $\frac{1}{2 r} \varphi B$ from the first to the second period if worker i receives the bonus. In turn, effort of a purely selfish worker i decreases by $\frac{1}{2 r}\left(-\beta_{T} \cdot B\right)$ if worker $\mathrm{j}$ receives the bonus since there is no compensating effect on the perceived kindness of the firm by feeling delighted for the other worker. Spiteful preferences which put a negative weight of the other worker's material payoffs, can be captured by the model assuming an $m<0$. If the other worker " $\mathrm{j}$ " receives the bonus, the effort of the spiteful worker "i" changes by $\frac{1}{2 r}\left(\varphi \cdot m \cdot B+\left(-\beta_{T} \cdot B\right)\right)$. Hence, the negative effect of "envy" due to disadvantageous wage inequality on the perceived kindness of the firm gets further amplified by the spitefulness. The total effect on worker i's effort in case of spiteful $(m<0)$ preferences will be negative if $\varphi \cdot m<\beta_{T}$ which automatically holds for $\varphi>0$.

\section{B.1.5 Calibration on experimental data}

The model shall serve as a structural micro-foundation for the reduced-form estimation with observed effort as the outcome variable. The identification strategy leads to under-identification of our key theoretical parameters. We would like to estimate the following set of parameters: $\left\{\varphi l ; \varphi m ; \alpha_{T} ; \beta_{T}\right\}$, whereof $\beta_{T} ; \alpha_{T}$ are vectors containing a unique parameter related to advantageous and disadvantageous inequality aversion, respectively, for each treatment. We only have seven treatment conditions in addition to the Control treatment: The Double Bonus condition and the three other treatment conditions where we observe effort levels under both, advantageous and disadvantageous wage inequality. The under-identification is due to the fact that, in our setup, we can only observe $\beta_{T}$ together with $l$ (weight of the own wage in gift exchange part), and $\alpha_{T}$ together with $m$ (weight of the other worker's wage in the gift exchange part), but we cannot observe, say, $\beta_{T}$ together with $m$, because we do not have the possibility to compare treatments with the same size of inequality but at the same time different size of the bonus. Due to those limitations, we assume $m=0$. This means that the worker experiences a gift exchange or contenment effect only with respect to oneself, but not with respect to the other worker. This assumption seems relatively mild in the context of our theoretical framework.

We also assume that the parameter $r$ from the quadratic effort cost function is a normally distributed random variable, which we rescale to have mean 1 . In order to recover the parameters of our theoretical model from the observed behavior in the experiment, we estimate a fixed-effects regression model with the average hourly effort

(either measured in characters, entries or correct entries) $y_{i t}$ in the two periods, given 
by the morning and the afternoon session, as dependent variable. To be precise, we estimate the following differences-in-differences regression:

$$
\begin{aligned}
y_{i t}=b_{0} & +\mu_{i}+b_{1}(\text { Double } \times a)+\sum_{T} b_{2_{T}} \cdot\left(\text { Advantaged }_{T} \times a\right) \\
& +\sum_{T} b_{3_{T}}\left(\text { Disadvantaged }_{T} \times a\right)+\gamma \cdot a+\epsilon_{i t}
\end{aligned}
$$

to calibrate our model. This differences-in-differences approach eliminates the estimation of some unobservable parameters, such as $w_{\text {norm }}$. While in the simplified world of our theoretical model, the intercept would be zero, the constant term $b_{0}$ which corresponds to the change in effort in the Control group captures effects not accounted for in the theoretical model (e.g. learning and/or fatigue effects, model parameter $\tilde{L}$ ). Hence, the Control group serves as the reference category ${ }^{19}$ and enables us to get rid of the $\tilde{L}$ function. The indicator functions for each single-bonus treatment are also included as vectors. The coefficient vectors $b_{2_{T}}$ and $b_{3_{T}}$ contain the regression coefficients from each of the single-bonus treatments in the afternoon. Due to the unobservability of effort costs, we assume $r=1$ in our quadratic cost function such that $c(e)=e^{2}$. The remaining coefficients allow to identify the parameters $\varphi, \alpha_{T}$ and $\beta_{T}$. The parameters $\alpha_{T}$ and $\beta_{T}$ defining inequality aversion can be inferred for each single-bonus treatment separately to identify differences in the source of horizontal inequality.

\section{B.1.6 Relating regression coefficents to model parameters}

Simplification: $m=0 ; l=1$ Our estimated regression coefficients can be related to the theoretical parameters from the model equations as follows. We take the difference in optimal effort as given by the model solution from the model subsection between the first and second period and impose the simplifying restrictions. From the observed effort change in the Double Bonus condition where no payoff inequality arises we arrive at an expression to determine the product $\varphi$. This defines the reaction of worker effort to a symmetric pay rise without wage inequality.

$$
\Delta e_{\text {Double }}=b_{1}=\frac{1}{2 b} \varphi\left(w+B-w_{\text {norm }}\right)-\frac{1}{2 b} \varphi\left(w-w_{\text {norm }}\right)=\frac{1}{2 b} \varphi \cdot B \Longleftrightarrow \varphi=b_{1} \frac{2 b}{B} .
$$

\footnotetext{
${ }^{19}$ Without adding controls this is equivalent to compare the conditional means of the difference in provided effort levels between the treatment conditions.
} 
Applying the same procedure for the difference in effort when either receiving or not receiving the bonus, we can express the remaining theoretical model parameters in terms of the fitted coefficients $b_{1}, b_{2_{T}}$ and $b_{3_{T}}$ (matching the $b^{\prime} s$ from the regression model) after rearranging equations.

$$
\begin{gathered}
\Delta e_{\text {Advantaged }_{T}}=b_{2}=\frac{1}{2 b}(\varphi+(-\beta)) \cdot B=b_{1}-\beta_{T} \cdot \frac{B}{2 b} \Longleftrightarrow \beta_{T}=\frac{2 b \cdot\left(b_{1}-b_{2}\right)}{B}(18) \\
\Delta e_{\text {Disadvantaged }_{T}}=b_{3}=\frac{1}{2 b}\left(\varphi+\left(-\alpha_{T}\right)\right) \cdot B \Longleftrightarrow \alpha_{T}=-b_{3} \cdot \frac{2 b}{B}
\end{gathered}
$$

\section{B.1.7 Post-experimental questionnaire: Satisfaction analysis}

\begin{tabular}{|c|c|c|c|c|}
\hline & (1) & $(2)$ & $(3)$ & (4) \\
\hline & $\begin{array}{l}\text { Payment } \\
\text { Adequate }\end{array}$ & $\begin{array}{l}\text { Treatment } \\
\text { Fair }\end{array}$ & $\begin{array}{c}\text { Own profits } \\
\text { deserved }\end{array}$ & $\begin{array}{c}\text { Other's profits } \\
\text { deserved }\end{array}$ \\
\hline Double & $\begin{array}{c}0.135 \\
(0.085)\end{array}$ & $\begin{array}{l}0.135 \\
(0.085)\end{array}$ & $\begin{array}{l}0.219^{*} \\
(0.124)\end{array}$ & $\begin{array}{c}0.220 \\
(0.150)\end{array}$ \\
\hline Arbitrary & $\begin{array}{l}-0.013 \\
(0.115)\end{array}$ & $\begin{array}{l}-0.229^{*} \\
(0.136)\end{array}$ & $\begin{array}{l}0.0456 \\
(0.141)\end{array}$ & $\begin{array}{l}-0.269 \\
(0.195)\end{array}$ \\
\hline Productivity & $\begin{array}{l}0.083 \\
(0.090)\end{array}$ & $\begin{array}{c}0.033 \\
(0.096)\end{array}$ & $\begin{array}{l}0.204^{*} \\
(0.121)\end{array}$ & $\begin{array}{l}0.041 \\
(0.154)\end{array}$ \\
\hline Needs & $\begin{array}{c}0.008 \\
(0.098)\end{array}$ & $\begin{array}{l}-0.061 \\
(0.106)\end{array}$ & $\begin{array}{l}0.130 \\
(0.128)\end{array}$ & $\begin{array}{l}-0.008 \\
(0.152)\end{array}$ \\
\hline Constant & $\begin{array}{c}3.865^{* * * *} \\
(0.085)\end{array}$ & $\begin{array}{c}3.865^{* * * * *} \\
(0.085)\end{array}$ & $\begin{array}{c}3.743^{* * * *} \\
(0.118)\end{array}$ & $\begin{array}{c}3.700^{* * * *} \\
(0.140)\end{array}$ \\
\hline Obs. & 228 & 233 & 224 & 212 \\
\hline $\begin{array}{l}\mathrm{R} 2 \\
\text { Hypothesis tests (p-values) }\end{array}$ & 0.0145 & 0.0447 & 0.0337 & 0.0527 \\
\hline Double $=$ Control & 0.113 & 0.114 & 0.079 & 0.144 \\
\hline Arbitrary $=$ Control & 0.910 & 0.095 & 0.748 & 0.171 \\
\hline Arbitrary $=$ Double & 0.062 & 0.001 & 0.048 & 0.001 \\
\hline Arbitrary $=$ Productivity & 0.256 & 0.025 & 0.061 & 0.041 \\
\hline Arbitrary $=$ Needs & 0.822 & 0.181 & 0.366 & 0.079 \\
\hline Productivity $=$ Control & 0.358 & 0.728 & 0.096 & 0.792 \\
\hline Productivity $=$ Double & 0.072 & 0.024 & 0.751 & 0.031 \\
\hline Productivity $=$ Needs & 0.195 & 0.228 & 0.208 & 0.575 \\
\hline Needs $=$ Control & 0.936 & 0.565 & 0.312 & 0.960 \\
\hline Needs $=$ Double & 0.011 & 0.003 & 0.158 & 0.004 \\
\hline
\end{tabular}

Table B.5: Regressions: Satisfaction Questions (Pooled Treatment Conditions)

Notes: Table shows OLS regression results from post-experimental questionnaire. p-values for pairwise tests between treatment conditions reported. Standard errors (clustered at session level) in parentheses. Column (1)-(4) have the answer score (1 absolutely disagree - 4 absolutely agree) to the following statements as dependent variable. (1) The payment I received was adequate. (2) The treatment of the two persons hired was fair. (3) The earnings I received in the second part of the day were deserved. (4) The earnings received by my coworker in the second part of the day were deserved. 
Table B.6: Regressions: Satisfaction Questions

\begin{tabular}{|c|c|c|c|c|}
\hline & $(1)$ & $(2)$ & $(3)$ & $(4)$ \\
\hline Double & $\begin{array}{l}0.135 \\
(0.085)\end{array}$ & $\begin{array}{l}0.135 \\
(0.085)\end{array}$ & $\begin{array}{l}0.219^{*} \\
(0.124)\end{array}$ & $\begin{array}{c}0.220 \\
(0.151)\end{array}$ \\
\hline Arbitrary $\times$ NB & $\begin{array}{l}-0.013 \\
(0.144)\end{array}$ & $\begin{array}{l}-0.346^{*} \\
(0.192)\end{array}$ & $\begin{array}{c}0.057 \\
(0.155)\end{array}$ & $\begin{array}{l}-0.140 \\
(0.224)\end{array}$ \\
\hline Arbitrary $\times \mathrm{B}$ & $\begin{array}{l}-0.013 \\
(0.144)\end{array}$ & $\begin{array}{l}-0.115 \\
(0.158)\end{array}$ & $\begin{array}{l}0.035 \\
(0.171)\end{array}$ & $\begin{array}{l}-0.392 \\
(0.244)\end{array}$ \\
\hline Productivity $\times$ NB & $\begin{array}{c}0.024 \\
(0.105)\end{array}$ & $\begin{array}{l}-0.043 \\
(0.124)\end{array}$ & $\begin{array}{c}0.183 \\
(0.129)\end{array}$ & $\begin{array}{c}0.069 \\
(0.165)\end{array}$ \\
\hline Productivity $\times \mathrm{B}$ & $\begin{array}{c}0.135 \\
(0.085)\end{array}$ & $\begin{array}{c}0.103 \\
(0.091)\end{array}$ & $\begin{array}{l}0.223^{*} \\
(0.124)\end{array}$ & $\begin{array}{l}0.0143 \\
(0.174)\end{array}$ \\
\hline Needs $\times$ NB & $\begin{array}{l}-0.013 \\
(0.110)\end{array}$ & $\begin{array}{l}-0.198 \\
(0.16)\end{array}$ & $\begin{array}{l}0.142 \\
(0.146)\end{array}$ & $\begin{array}{l}-0.033 \\
(0.182)\end{array}$ \\
\hline Needs $\times$ B & $\begin{array}{c}0.028 \\
(0.116)\end{array}$ & $\begin{array}{l}0.0662 \\
(0.098)\end{array}$ & $\begin{array}{c}0.119 \\
(0.135)\end{array}$ & $\begin{array}{l}0.0143 \\
(0.166)\end{array}$ \\
\hline Constant & $\begin{array}{c}3.865^{* * * *} \\
(0.085)\end{array}$ & $\begin{array}{c}3.865^{* * * *} \\
(0.085)\end{array}$ & $\begin{array}{c}3.743^{* * * * *} \\
(0.119)\end{array}$ & $\begin{array}{c}3.700^{* * * *} \\
(0.141)\end{array}$ \\
\hline Obs. & 228 & 233 & 224 & 212 \\
\hline $\begin{array}{l}\text { R2 } \\
\text { Hypothesis tests (p-values) }\end{array}$ & 0.019 & 0.074 & 0.035 & 0.062 \\
\hline Double $=$ Control & 0.115 & 0.116 & 0.081 & 0.147 \\
\hline Arbitrary NB $=$ Control & 0.928 & 0.074 & 0.713 & 0.534 \\
\hline Productivity $\mathrm{NB}=$ Control & 0.820 & 0.727 & 0.159 & 0.675 \\
\hline Needs NB $=$ Control & 0.906 & 0.207 & 0.333 & 0.855 \\
\hline Arbitrary $\mathrm{B}=$ Control & 0.928 & 0.468 & 0.839 & 0.110 \\
\hline Productivity $\mathrm{B}=$ Control & 0.115 & 0.262 & 0.074 & 0.935 \\
\hline Needs B $=$ Control & 0.810 & 0.500 & 0.380 & 0.932 \\
\hline Arbitrary NB $=$ Double & 0.203 & 0.006 & 0.133 & 0.050 \\
\hline Productivity NB $=$ Double & 0.074 & 0.050 & 0.577 & 0.132 \\
\hline Needs NB $=$ Double & 0.036 & 0.012 & 0.408 & 0.048 \\
\hline Double $=$ Arbitary B & 0.203 & 0.062 & 0.157 & 0.003 \\
\hline Double $=$ Productivity $\mathrm{B}$ & 1.000 & 0.321 & 0.938 & 0.074 \\
\hline Double $=$ Needs B & 0.176 & 0.153 & 0.189 & 0.046 \\
\hline Arbitrary $\mathrm{B}=$ Productivity $\mathrm{B}$ & 0.203 & 0.113 & 0.146 & 0.071 \\
\hline Arbitrary $\mathrm{B}=$ Needs $\mathrm{B}$ & 0.770 & 0.201 & 0.547 & 0.063 \\
\hline Needs $\mathrm{B}=$ Productivity $\mathrm{B}$ & 0.176 & 0.527 & 0.164 & 1.000 \\
\hline Arbitrary NB $=$ Productivity NB & 0.778 & 0.121 & 0.265 & 0.282 \\
\hline Arbitary NB $=$ Needs NB & 1.000 & 0.494 & 0.520 & 0.610 \\
\hline Needs NB $=$ Productivity NB & 0.691 & 0.332 & 0.677 & 0.474 \\
\hline
\end{tabular}

Notes: Table shows OLS regression results from post-experimental questionnaire. p-values for pairwise tests between treatment conditions reported. Standard errors (clustered at session level) in parentheses. Column (1)-(4) have the answer score ( 1 absolutely disagree - 4 absolutely agree) to the following statements as dependent variable. (1) The payment I received was adequate. (2) The treatment of the two persons hired was fair. (3) The earnings I received in the second part of the day were deserved. (4) The earnings received by my coworker in the second part of the day were deserved. 


\section{B.1.8 Additional Regressions}

Table B.7: Panel Data Fixed-Effects Model Regressions

\begin{tabular}{|c|c|c|c|c|c|}
\hline & \multicolumn{2}{|c|}{ Whole Sample } & \multicolumn{3}{|c|}{ Outliers removed } \\
\hline & (1) & $(2)$ & $(3)$ & $(4)$ & $(5)$ \\
\hline \multirow{3}{*}{ Double $\times$ Afternoon } & Entries & Correct entries & Characters & Entries & Correct entries \\
\hline & $-5.885^{* *}$ & $-5.645^{* *}$ & $-127.101^{* * * *}$ & $-4.676^{* *}$ & $-4.434^{*}$ \\
\hline & $(2.58)$ & $(2.57)$ & $(37.24)$ & $(2.27)$ & $(2.25)$ \\
\hline \multirow{2}{*}{ Arbitrary NB $\times$ Afternoon } & -0.324 & -0.151 & 1.94 & 0.885 & 1.06 \\
\hline & $(2.65)$ & $(2.57)$ & $(44.56)$ & $(2.35)$ & $(2.25)$ \\
\hline \multirow[t]{2}{*}{ Arbitrary $\mathrm{B} \times$ Afternoon } & $-5.807^{*}$ & $-5.506^{*}$ & $-90.637^{*}$ & $-4.598^{*}$ & -4.295 \\
\hline & $(3.00)$ & $(2.96)$ & $(49.60)$ & $(2.74)$ & $(2.68)$ \\
\hline \multirow[t]{2}{*}{ Productivity NB $\times$ Afternoon } & -0.797 & -0.936 & -30.451 & 0.411 & 0.275 \\
\hline & $(3.14)$ & $(3.12)$ & $(49.15)$ & $(2.89)$ & $(2.86)$ \\
\hline \multirow[t]{2}{*}{ Productivity $\mathrm{B} \times$ Afternoon } & -3.658 & -3.993 & -56.338 & -2.449 & -2.781 \\
\hline & $(2.55)$ & $(2.55)$ & $(42.71)$ & $(2.24)$ & $(2.22)$ \\
\hline \multirow[t]{2}{*}{ Needs NB $\times$ Afternoon } & $-9.151^{* * *}$ & $-8.713^{* * *}$ & $-147.819^{* * *}$ & $-7.942^{* * *}$ & $-7.501^{* * *}$ \\
\hline & $(2.96)$ & $(2.88)$ & $(45.30)$ & $(2.70)$ & $(2.60)$ \\
\hline \multirow[t]{2}{*}{ Needs B $\times$ Afternoon } & -4.031 & -3.805 & -79.254 & -2.868 & -2.665 \\
\hline & $(2.89)$ & $(2.82)$ & $(48.51)$ & $(2.67)$ & $(2.59)$ \\
\hline \multirow[t]{2}{*}{ Afternoon } & $9.410^{* * * *}$ & $8.799 * * * *$ & $149.171^{* * * *}$ & $8.202^{* * * *}$ & $7.588^{* * * *}$ \\
\hline & $(2.05)$ & $(2.01)$ & $(31.19)$ & $(1.64)$ & $(1.58)$ \\
\hline \multirow[t]{2}{*}{ Constant } & $55.178^{* * * *}$ & $54.138^{* * * *}$ & $968.748^{* * * *}$ & $55.278^{* * * *}$ & $54.235^{* * * *}$ \\
\hline & $(0.36)$ & $(0.35)$ & $(5.73)$ & $(0.34)$ & $(0.34)$ \\
\hline
\end{tabular}


Table B.7: Panel Data Fixed-Effects Model Regressions

\begin{tabular}{lccccc} 
& \multicolumn{2}{c}{ Whole Sample } & & Outliers removed \\
& $(1)$ & $(2)$ & $(3)$ & $(4)$ & $(5)$ \\
\hline No. Individuals & 236 & 236 & 234 & 234 & 234 \\
No. Clusters & 126 & 126 & 126 & 126 & 126 \\
Hypothesis tests (p-values) & & & & \\
Double = Arbitrary B & 0.977 & 0.959 & 0.405 & 0.977 & 0.959 \\
Double = Productivity B & 0.309 & 0.462 & 0.049 & 0.309 & 0.462 \\
Double = Needs B & 0.471 & 0.471 & 0.261 & 0.492 & 0.498 \\
Arbitrary B = Productivity B & 0.421 & 0.573 & 0.479 & 0.421 & 0.573 \\
Arbitrary B = Needs B & 0.553 & 0.564 & 0.832 & 0.570 & 0.587 \\
Needs B = Productivity B & 0.883 & 0.941 & 0.628 & 0.872 & 0.964 \\
Arbitrary NB = Productivity NB & 0.871 & 0.786 & 0.515 & 0.871 & 0.786 \\
Arbitary NB = Needs NB & 0.002 & 0.001 & 0.001 & 0.002 & 0.001 \\
Needs NB = Productivity NB & 0.010 & 0.015 & 0.021 & 0.010 & 0.015 \\
\hline
\end{tabular}

Notes: Table shows fixed-effects panel data regression results. The first three columns show the results for entries, and correct entries as dependent variable using the whole sample as in the main text. The remaining columns show the results for the same dependent variables plus characters when excluding observations whose change in effort lies outside of Tukey's outer fences (below or above the first or third quartile by three times the interquartile range, respectively), thus excluding severe outliers also visible in the ECDFs above. Clustered standard errors at the session (couple) level in parentheses. ${ }^{*} \mathrm{p}<$ $0.1,{ }^{* *} \mathrm{p}<0.05,{ }^{* * *} \mathrm{p}<0.01,{ }^{* * * *} \mathrm{p}<0.001$. 


\section{B.1.9 Rank-sum Tests: Differences-in-Differences across Treatment Conditions}

Table B.8 shows treatment effects calculated as pairwise differences in differences between treatment conditions. We compare the change in the treatment condition from the first column to the change in the treatment condition of the first row (differences in changes from morning to afternoon productivity across treatment conditions).

Table B.8: Treatment Effects by Treatment Condition

\begin{tabular}{|c|c|c|c|c|c|c|c|}
\hline & Control & Arbitrary B & Arbitrary NB & Productivity B & Productivity NB & Needs B & Needs NB \\
\hline Arbitrary B & $\begin{array}{c}-110.31 \\
(-65.33 \%)\end{array}$ & & & & & & \\
\hline p-value & 0.09 & & & & & & \\
\hline Arbitrary NB & $\begin{array}{c}-17.74 \\
(-10.50 \%)\end{array}$ & $\begin{array}{c}92.58 \\
(54.83 \%)\end{array}$ & & & & & \\
\hline p-value & 0.72 & 0.07 & & & & & \\
\hline Productivity B & $\begin{array}{c}-76.01 \\
(-45.02 \%)\end{array}$ & $\begin{array}{c}34.30 \\
(20.31 \%)\end{array}$ & $\begin{array}{c}-58.28 \\
(-34.51 \%)\end{array}$ & & & & \\
\hline p-value & 0.19 & 0.63 & 0.16 & & & & \\
\hline Productivity NB & $\begin{array}{c}-50.13 \\
(-29.69 \%)\end{array}$ & $\begin{array}{c}60.19 \\
(35.64 \%)\end{array}$ & $\begin{array}{c}-32.39 \\
(-19.18 \%)\end{array}$ & $\begin{array}{c}25.89 \\
(15.33 \%)\end{array}$ & & & \\
\hline p-value & 0.71 & 0.21 & 0.54 & 0.39 & & & \\
\hline Needs B & $\begin{array}{c}-131.27 \\
(-77.74 \%)\end{array}$ & $\begin{array}{c}-20.95 \\
(-12.41 \%)\end{array}$ & $\begin{array}{c}-113.53 \\
(-67.24 \%)\end{array}$ & $\begin{array}{c}-55.25 \\
(-32.72 \%)\end{array}$ & $\begin{array}{c}-81.14 \\
(-48.05 \%)\end{array}$ & & \\
\hline $\mathrm{p}$-value & 0.24 & 0.69 & 0.10 & 0.84 & 0.31 & & \\
\hline Needs NB & $\begin{array}{c}-167.49 \\
(-99.19 \%)\end{array}$ & $\begin{array}{c}-57.18 \\
(-33.86 \%)\end{array}$ & $\begin{array}{c}-149.76 \\
(-88.69 \%)\end{array}$ & $\begin{array}{c}-91.48 \\
(-54.18 \%)\end{array}$ & $\begin{array}{c}-117.37 \\
(-69.51 \%)\end{array}$ & $\begin{array}{c}-36.23 \\
(-21.46 \%)\end{array}$ & \\
\hline p-value & 0.00 & 0.27 & 0.00 & 0.08 & 0.02 & 0.15 & \\
\hline Double & $\begin{array}{c}-146.78 \\
(-86.93 \%)\end{array}$ & $\begin{array}{c}-36.46 \\
(-21.60 \%)\end{array}$ & $\begin{array}{c}-129.04 \\
(-76.42 \%)\end{array}$ & $\begin{array}{c}-70.76 \\
(-41.91 \%)\end{array}$ & $\begin{array}{c}96.65 \\
(57.24 \%)\end{array}$ & $\begin{array}{c}-15.51 \\
(-9.19 \%)\end{array}$ & $\begin{array}{c}-20.72 \\
(-12.27 \%)\end{array}$ \\
\hline p-value & 0.00 & 0.29 & 0.00 & 0.09 & 0.02 & 0.12 & 0.89 \\
\hline
\end{tabular}

Notes: ATE as difference in differences (afternoon-morning) between compared treatments in absolute and percentage terms. We compare the difference in the treatment condition from the first column relative to the difference in the treatment condition from the first row. p-values from non-parametric two-sided Wilcoxon rank-sum tests against the null hypothesis of equal distributions in the pairwise compared treatment groups. 


\section{B.2 Instructions and Experimental Protocol}

We report the experiment protocol and the instructions administered in the experiment in Sections B.2.1 to B.2.5. All the text read aloud to participants is reported in italics. In order to ensure that the same information was administered to participants across sessions, the lead research assistant would read most of such instructions from a written script. Section B.2.6 reports further notes to the assistants. Section B.2.7 reports the instruction sheet given to participants to carry out their task. Section B.2.8 reports the final questionnaire. The original script in Spanish is available upon request.

\section{B.2.1 Welcome}

The lead research assistant (RA1 henceforth) (or the other research assistant, RA2 henceforth) greets the pair of workers at the Business School faculty or at the Konrad Lorenz University entrance. We try to avoid them talking with each other. We take one of them into the faculty lounge while the other sits waiting outside. We hand out the informed consent form, asking them to read it and to sign it. Tell them to please wait quietly before the day work starts. When they are both present and have signed the consent form, the schedule of the working day can be explained to them.

(At the Faculty reception desk or at the Assistant office): Good morning guys, did you bring the copies of your electricity bills? Please give them to me.

(If a participant does not bring them, he/she is asked to please call someone at home who can send them to him/her).

Before we begin, I am going to ask you to please read these informed consent form, which is to assure you that all the information you provide us today will be treated confidentially. If you have any questions, please let me know, otherwise please enter your ID and today's date and sign.

Once the informed consent is signed, the participants are asked to enter the staff room and sit in front of the computer where the task is explained.

Good morning again, thank you very much for your interest in collaborating with us. My name is [State name of lead researcher], and here with me is [State name of the other research assistant present].

RA2 acknowledges the introduction.

I am going to read the following instructions from a written text, because I do not want to forget important details. The work for which we are hiring you is part of a research project conducted and funded by a consortium of universities. We want to send some questionnaires to residents of Bogotá. For that purpose, we need to prepare 
the labels with the data of the recipients. Additionally, we want it to be a casual sample of Bogotá residents and so we will use a version of the telephone directory to extract the addresses of the residents. Both of you are going to do the same task individually. You will stay in two different rooms. Each of you will be responsible for the room and the computer we give you, so we will ask you not to leave the room. If, for any reason, you do need to leave the room, I will give you shortly a phone number you can call. Laura/Daniel or I will come and stay in the rooms while you are out.

The work is divided into a two-hour session, a 15 minute break and then a threehour session. The hourly rate is \$15,000, which means that at the end of the five hours you will receive $\$ 75,000$. Your contract is for today only. That is, under the terms of this project, you will not be offered a new contract. Do you agree with these conditions? Now I will show you your task for this job.

RA2 shows the Excel sheet ADDRESSES.xslx.

On your computer you will find the file ADDRESSES, this is the file you have to fill in. This file has two columns, the City column, which will always be Bogotá because the directories are from Bogotá, and the Address column, which is the one you must fill in. Note that in the Address column, only the address goes, neither name nor telephone, if there is information of apartment, office, neighborhood, etc, include it, otherwise, only the address that appears. Now, where are you going to get the information to fill in the ADDRESSES file? From the COORDINATES file, which as its name indicates are search coordinates.

\section{RA2 opens the second Excel sheet COORDINATES.xlsx}

As you can see, the file has the columns Page, Column and Entry, so in this first case for example, you search in your directory for page 93, column 4 and entry number 4.

RA2 shows an exercise.

Do you have any questions, is everything clear? Well, then to verify that it is clear, please do this example yourself.

RA2 invites the participants to execute an example.

If that is clear, there is only one exceptional case and it is this:

RA2 shows an example of entries that have no address.

Suppose you check your file, and the coordinate is this one that has no address associated with it, in that case then, you jump to the next address, and you write down the next available address, you do not leave blanks in the database, but you just write down the next address. 
Well, finally I am going to ask you to please save each time you make an entry, either on the floppy disk icon or Control $+G$ so as not to lose information.

Now, I am going to accompany Participant 1 to the room. I will be right back for you (Participant 2).

\section{B.2.2 Morning Session}

(In the offices of each participant):

Well, here I leave you your two files, I leave you water and in this envelope I leave you the instruction sheet with all the information I gave you a moment ago, with more detail, and the phone number where you can call us for anything you need. If you don't have credit on your phone, you can use this cell phone. I leave you this envelope that has the example of how the labels we are going to print from the database you are helping us to build. So, it's $X X: X X$ (state time); we will come round in two hours to let you know that the first session is over.

As soon as she closes the door, RA1 starts the timer and calls RA2 to activate his/her stopwatch. RA2 is present in the assistant office, but does not speak to the participant.

Repeat last set of operations for the second participant.

\section{B.2.3 End of Morning Session}

Every hour, RA2 saves the file in a folder and takes note of the number of completed addresses (and the number of characters) and does a random check of its accuracy/error rate. After exactly two hours, RA1 and RA2 go into the two offices separately.

Hi, the first 2-hour session is over. I brought you a snack, do you want to go to the bathroom or something? While you're out I'm going to save your work. I'm going to ask you to please stay away from the computer during these 15 minutes and exercise your hands to avoid fatigue. I will come back in 15 minutes for you to start the second session.

RA1 and RA2 take care that participants do not communicate with each other and go to the bathroom one at a time. They save the Excel file on the USB stick. RA2 computes relative productivity in Productivity Treatment; checks home quality as reported in the utility bill in Need Treatment; performs an unbiased random draw among the two workers in the Arbitrary treatment. It is then determined which participant will receive the bonus and who will not in the Treatment conditions. After 15 minutes, RA1 goes to each office and convenes the two participants to the staff room. RA2 is present 
in the teachers' room. When the two participants arrive, RA2 leaves the assistant office to watch the classrooms.

\section{B.2.4 Treatment}

The treatment sequence across sessions is the following:

1. Productivity Treatment

2. Need Treatment

3. Productivity Treatment

4. Arbitrary Treatment

5. Double Bonus Condition

6. Control Condition

7. Arbitrary Treatment

8. Needs Treatment

9. Control Condition

10. Double Bonus Condition

(In the Assistant room):

1. Control Condition: We are ready to proceed with work. The work is the same as in the first session, but the duration of the second session will be 3 hours and the salary will be the same as in the first part.

2. Productivity Treatment: We are ready to proceed with work. The work is the same as the first session, but the duration of the second session will be 3 hours. The salary for today's afternoon will be 15000 per hour as in the morning. However, the research director wants to pay a bonus of 25,000 pesos to one of you. To decide who would get the bonus we reviewed the number of entries and characters you completed in the first session and taking those criteria into account, then you (indicating the participant receiving the bonus) will receive the bonus, which means we will pay you $\$ 75,000$ for the five hours plus a \$25,000 bonus for a total of $\$ 100,000$. In the meantime, you (indicating the participant not receiving the bonus) will receive the $\$ 75,000$ that we agreed upon this morning.

3. Needs Treatment: We are ready to proceed with work. The work is the same as the first session, but the duration of the second session will be 3 hours. The salary for today's afternoon will be 15000 per hour as in the morning. However, the research director wants to pay a bonus of 25000 pesos to one of the couple's workers. To decide who would get the bonus we reviewed the socio-economic strata of your houses, the poverty level of the locality where you live and their age. Taking those criteria into account, then you (indicating the participant receiving the bonus) will receive the bonus, which means that we will pay you $\$ 75,000$ for the five hours 
plus a \$25,000 bonus for a total of \$100,000. In the meantime, you (indicating the participant not receiving the bonus) will receive the $\$ 75,000$ that we agreed upon this morning.

4. Arbitrary Treatment: We are ready to proceed with work. The work is the same as the first session, but the duration of the second session will be 3 hours. The salary for today's afternoon will be 15000 per hour as in the morning. However, the research director wants to pay a bonus to one of you. Unfortunately, he did not have time to review who completed the most entries in the first session, or your socioeconomic status, age or other criteria. He chose you (indicating the participant receiving the bonus) to receive the bonus, which means we will pay you $\$ 75,000$ for the five hours plus a $\$ 25,000$ bonus for a total of $\$ 100,000$. On the other hand, you (indicating the participant receiving the bonus) will receive the $\$ 75,000$ that we agreed on this morning.

5. Double Bonus Condition: We are ready to proceed with the work. The work is the same as the first session, but the duration of the second session will be 3 hours. The salary for today's afternoon will be 15,000 per hour as in the morning. However, the research director wants to pay you both a bonus of 25,000 pesos, which means we will pay you \$75,000 for the five hours plus a \$25,000 bonus for a total of $\$ 100,000$.

Thank you. I will now take you to your offices.

RA1 separately takes the workers to their offices.

\section{B.2.5 Afternoon session}

As of now, the second session begins, it is $X X: X X$ at $X X: X X$ (state the time) and in three hours we will finish the second work session. Thank you.

Every hour, RA2 saves the file in a folder and takes note of the number of completed addresses (and the number of characters) and does a random check of its accuracy/error rate. After exactly three hours, RA2 goes to the first office:

The 3 hours are up. We would be grateful if you could answer this evaluation questionnaire. The questionnaire will be associated with a code so that your identity does not appear and the confidentiality of the information you provide is guaranteed. We will collect your questionnaire in this box.

Show ballot box, save all data in the USB flash drive and hand in the questionnaire.

I will be back in a few minutes with the money. In the meantime, please fill out the questionnaire. 
RA2 goes to the other office and repeats. After 3-4 minutes she comes back to the first office.

Thank you very much for your cooperation. Please insert the questionnaire in the ballot box. Here is your money. Please confirm that it is complete (wait for the money to be counted). Now please fill out the receipt and I will take you to the elevator.

RA2 brings Worker 1 to the elevator, then repeats the process with Worker 2.

\section{B.2.6 Further notes for assistants}

\section{Important tips when interacting with participants}

1. Do not mention anything related to other workers.

2. Ask immediately for their CV (if for some reason this was not sent with the email) and the electricity bill.

3. Mention that it is a one-day job; there will be no possibility of contract extension.

4. Do not give any reference as to what we are expecting in terms of productivity.

5. Do not anticipate anything related to the bonus in the second session.

6. Always give the same answers to similar questions.

7. If you don't know what to say, stress that you are the project assistant and are only executing directives from the project coordinator; don't make anything up!

8. If a participant does not show up, find a university student willing to work.

\section{Answers to Frequently Asked Questions}

- Why do I have to fill out the consent form, and why the questionnaire?

The consent serves as a statement that you are aware of all procedures and the use of the data. The questionnaire is solely for our evaluation of working conditions and your satisfaction.

- What happens if I cannot complete all the addresses on my sheet?

Don't worry, nothing happens.

- I am entitled to an hour's break.

Since this is not a full workday, we would expect 15 minutes of rest to be sufficient. We also do this so that a student has more time to attend classes. However, if you need a longer break, we can accommodate it.

\section{B.2.7 Task Instruction Sheet}

1. Open the sheet COORDINATES SURNAME.xlsx

2. Read the entries in the given order (starting with line 1, then 2 , then 3 etc.).

3. The first number is the page number in the telephone directory.

4. The second number is the column number in the page (starting from the left). 
5. The third number is the address line starting from the top. If the number is greater than the number of addresses, continue counting (same column) from top to bottom until you reach the number that appears in COORDINATES SURNAME.xlsx.

Figure B.4: Task Example

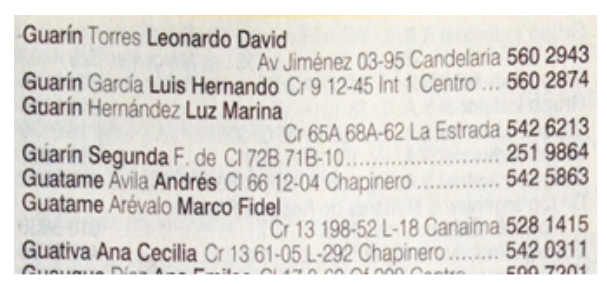

1. If the corresponding entry does not have an address but only a telephone number, please record the subsequent address, i.e. that in the next entry.

2. Open the sheet ADDRESSES SURNAME.xlsx

3. Fill in the box in the "Address" column.

4. Fill in the "City" box by typing "Bogota".

5. Save.

6. Your room is reserved, if anyone asks something, answer that it is reserved by Professor Castiblanco from the Business School.

7. Remember that you are responsible for the computer and the classroom.

8. If you have any questions, please call immediately 314306 XX XX XX.

\section{B.2.8 Final Questionnaire}

Code:

Q1) Sex: M F

Q2) Age: years

Q3) What is your marital status?

- Married/Living with partner

- Single

- Separated/Divorced/Widow

Q4) According to your utility bills, what is the tier of your current home or neighborhood?

\begin{tabular}{|l|l|l|l|l|l|}
\hline 1 & 2 & 3 & 4 & 5 & 6 \\
\hline
\end{tabular}

Q5) What is your level of education? 
- None

- Primary School

- High school

- Some university, but no graduation

- Technical

- University degree

Q6) What is your father's level of education?

- None

- Primary School

- High school

- Some university, but no graduation

- Technical

- University degree

Q7) What is your mother's level of education?

- None

- Primary School

- High school

- Some university, but no graduation

- Technical

- University degree

Q8) What is your occupation?

- Student

- Unemployed, retired, housewife, househusband

- Other (specify)

Q9) For each of the statements below, please indicate your level of agreement or disagreement.

a. The work organization was effective.

\begin{tabular}{|l|l|l|l|l|l|}
\hline Strongly disagree & 1 & 2 & 3 & 4 & Strongly agree \\
\hline
\end{tabular}

b. The payment I received was appropriate.

\begin{tabular}{|l|l|l|l|l|l|}
\hline Strongly disagree & 1 & 2 & 3 & 4 & Strongly agree \\
\hline
\end{tabular}

c. The treatment received by the two people hired was equitable.

\begin{tabular}{|l|l|l|l|l|l|}
\hline Strongly disagree & 1 & 2 & 3 & 4 & Strongly agree \\
\hline
\end{tabular}

d. The earnings I received in the second part of the workday were well deserved. 


\begin{tabular}{|l|l|l|l|l|l|}
\hline Strongly disagree & 1 & 2 & 3 & 4 & Strongly agree \\
\hline
\end{tabular}

e. The earnings that the other person hired in the second part of the workday received were well deserved.

\begin{tabular}{|l|l|l|l|l|l|}
\hline Strongly disagree & 1 & 2 & 3 & 4 & Strongly agree \\
\hline
\end{tabular}

Q10) Below are some possible reasons why some individuals succeed and others do not. On a scale of one to four, where one represents "not important" and five "very important"; indicate, in determining a person's success, how important it is:

a. Money inherited from family.

\begin{tabular}{|l|l|l|l|l|l|}
\hline Not important & 1 & 2 & 3 & 4 & Very important \\
\hline
\end{tabular}

b. Hard work and initiative.

\begin{tabular}{|l|l|l|l|l|l|}
\hline Not important & 1 & 2 & 3 & 4 & Very important \\
\hline
\end{tabular}

c. Connections and familiarity with the right people.

\begin{tabular}{|l|l|l|l|l|l|}
\hline Not important & 1 & 2 & 3 & 4 & Very important \\
\hline
\end{tabular}

Q11) Among the following two factors, which factor do you consider to be more important for a person to be in a state of poverty?

- Lack of effort and work commitment on the part of the person.

- Luck or events that are not in the person's control

Q12) How much do you agree that the government needs to reduce the gap between rich and poor, either by raising taxes for the rich or by providing income assistance to the poorest? Please indicate how strongly you agree by marking a number from one to four on the scale below, where one indicates "strongly disagree" and four indicates "strongly agree".

\begin{tabular}{|l|l|l|l|l|l|}
\hline Strongly disagree & 1 & 2 & 3 & 4 & Strongly agree \\
\hline
\end{tabular}

Q13) How did you hear about this project? You can check more than one option.

- Through a poster

- By email

- Through social media

- Through a friend

- Through another person who was hired

- Other (specify)

Q14) Please express, if you wish, your opinions about this workday. Thank you for your cooperation. 